
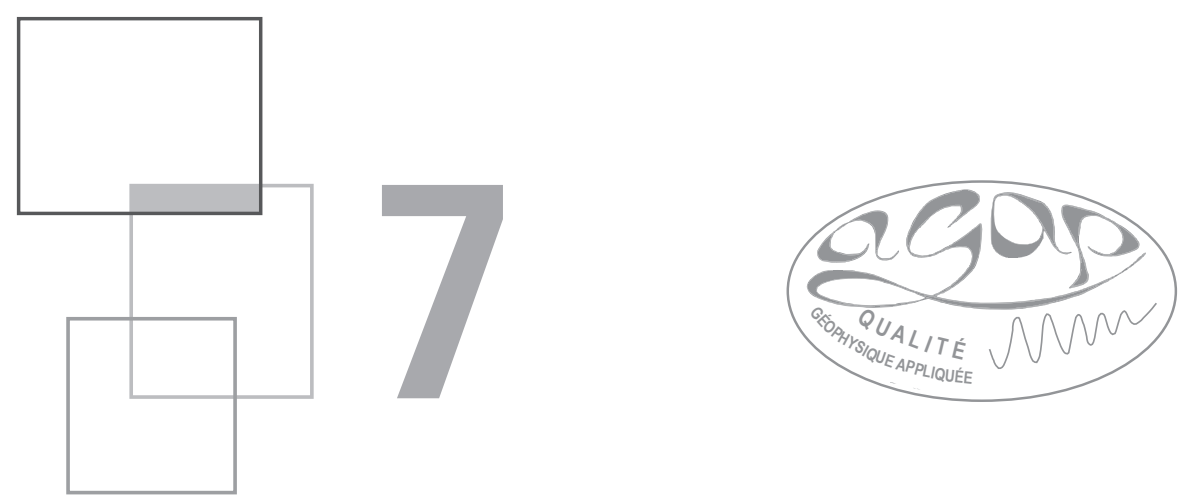

\title{
Integrated seismic study
}

\section{Focus on "Cigéo", the French geological repository project}

\author{
J.-L. Mari and B. Yven
}

"Cigéo" is the French Geological Repository Project dedicated to the disposal of high-level (HL) and intermediate-level long-lived (IL-LL) radioactive waste in a Callovo-Oxfordian argillaceous formation. The area is located in the eastern part of the Paris Basin and has been extensively studied by the French national radioactive waste management agency (Andra) for the past 25 years (Andra, 2005; Andra, 2009; Andra 2016).

In 2010, a zone of interest for a detailed survey, located a few kilometres from the Bure Underground Research Laboratory, was defined. It was chosen to be a site for

This chapter of Seismic Imaging: a practical approach is published under Open Source Creative Commons License CC-BY-NC-ND allowing non-commercial use, distribution, reproduction of the text, via any medium, provided the source is cited.

(C) EDP Sciences, 2019

DOI: 10.1051/978-2-7598-2351-2.c009 
underground facilities (Andra, 2009). A 3D seismic survey $\left(37 \mathrm{~km}^{2}\right)$ was recorded to verify the geometry and properties of the clay formation and of the underlying and overlying limestone formations. In addition to the 3D seismic campaign, drilling and geophysical borehole measurements, including vertical seismic profiles (VSP), and up-hole investigations were performed to calibrate the 3D seismic blocks and to perform the time-to-depth conversion.

After presenting the geological setting, we describe the survey design and the processing applied to the dataset. We describe a method that could be developed to build a geo-model in depth, using pre-stack time migration, elastic inversion in time and the relationship between P-wave velocity and acoustic impedance. We also show how petro-physical studies could be conducted. 2D and 3D lines are used to illustrate the potential of the proposed procedure for estimating density $(\rho)$, velocity (Vp, Vs), distributions of mechanical ( $\mathrm{Q}$ factor, dynamic and static moduli) and petro-physical parameters (porosity, specific surface, permeability indicator). This chapter is a review of published literature. The data and parameter values contained in this chapter do not predetermine the use that will be made of them for design and safety analyses.

\subsection{Geological setting}

The Meuse/Haute-Marne sector is located in the eastern part of the Paris Basin (Figure 7.1). The sedimentary succession shows a simple, monocline structure, dipping towards the centre of the basin $(\mathrm{NW})$ which follows the general structure of the basin.

The sector north of the Haute-Marne and south of the Meuse (Figure 7.1) constitutes a geologically simple area of the Paris Basin, with a succession of layers of limestone, marl and clay rock deposited in ancient ocean. The dip of the layers is low, around $1^{\circ}$ to $1.5^{\circ}$ towards the north-west. The Callovo-Oxfordian formation was chosen to host the Cigéo underground installation. It comprises 155 million year old clay rock, which is at least 130 meters thick and located at a depth of between 400 and 600 meters. It is referred to herein as the Callovo-Oxfordian argillites (Cox) formation. The selection of this Callovo-Oxfordian formation was based on its depth, low permeability, weak diffusion of solutes, high retention capacities and its significant thickness, which is favourable to the limitation of radionuclide migration from the Callovo-Oxfordian, into the surrounding formations, and then the biosphere, for a time scale of at least several hundred thousand years.

The top of the Cox formation is more carbonate-rich, with interbedded clayey layers and carbonate rock. The Cox is more homogeneous in its central part with a clay-mineral concentration of $45-50 \%$, which corresponds to a maximum of flooding within the area. A detailed study of the spatial variability of the Cox geological and physical properties may be found in Garcia et al. (2011). This formation is 
embedded by two thick carbonated units: Dogger and Oxfordian. The Dogger (Bathonian, Bajocian) corresponds to the development of carbonate platforms in the Paris Basin (Gaumet, 1997; Purser, 1980, Brigaud, 2014). The clayey formation is separated from the Dogger limestone by a regional paleo-erosion surface. The Bathonian limestone formation is the first aquifer encountered in the Jurassic succession.

Above the Cox, an Oxfordian (Middle and Late) platform was found, developed with reefs and bioclastic facies. The Oxfordian limestone formation is a second Jurassic aquifer. The two aquifers are studied in this work. In the area investigated by seismic surveying, the outcropping formations are Kimmeridgian marls and Kimmeridgian and Tithonian limestone with a thin deposit of Cretaceous. Figure 7.2 gives the geological description of the Jurassic and Triassic series at well EST433 and the location of the interpreted seismic horizons (Landrein et al., 2014; Mari and Yven, 2014).

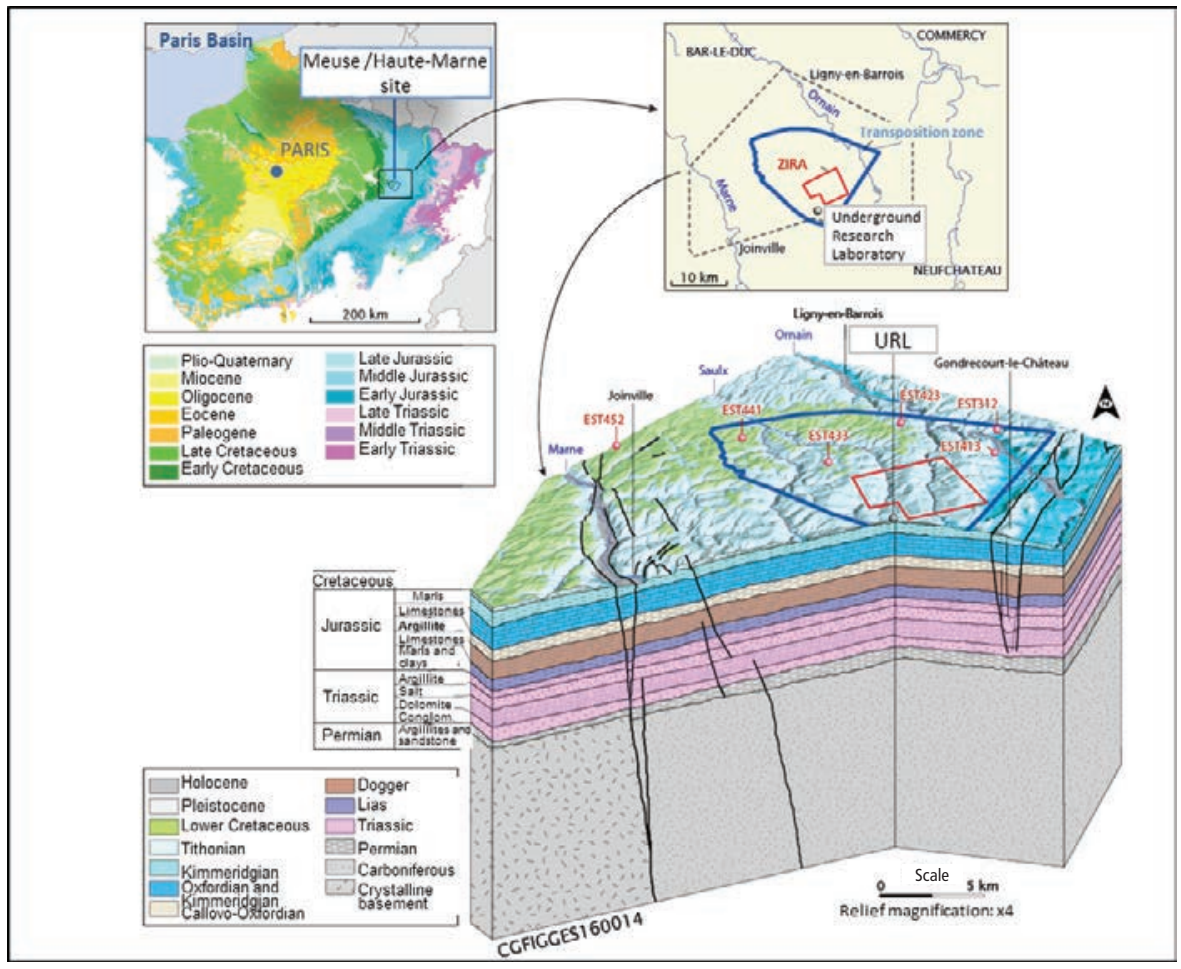

Figure 7.1 Simplified geological map of the Paris Basin showing the location of the Meuse/Haute-Marne site and Andra's underground research laboratory (URL). 


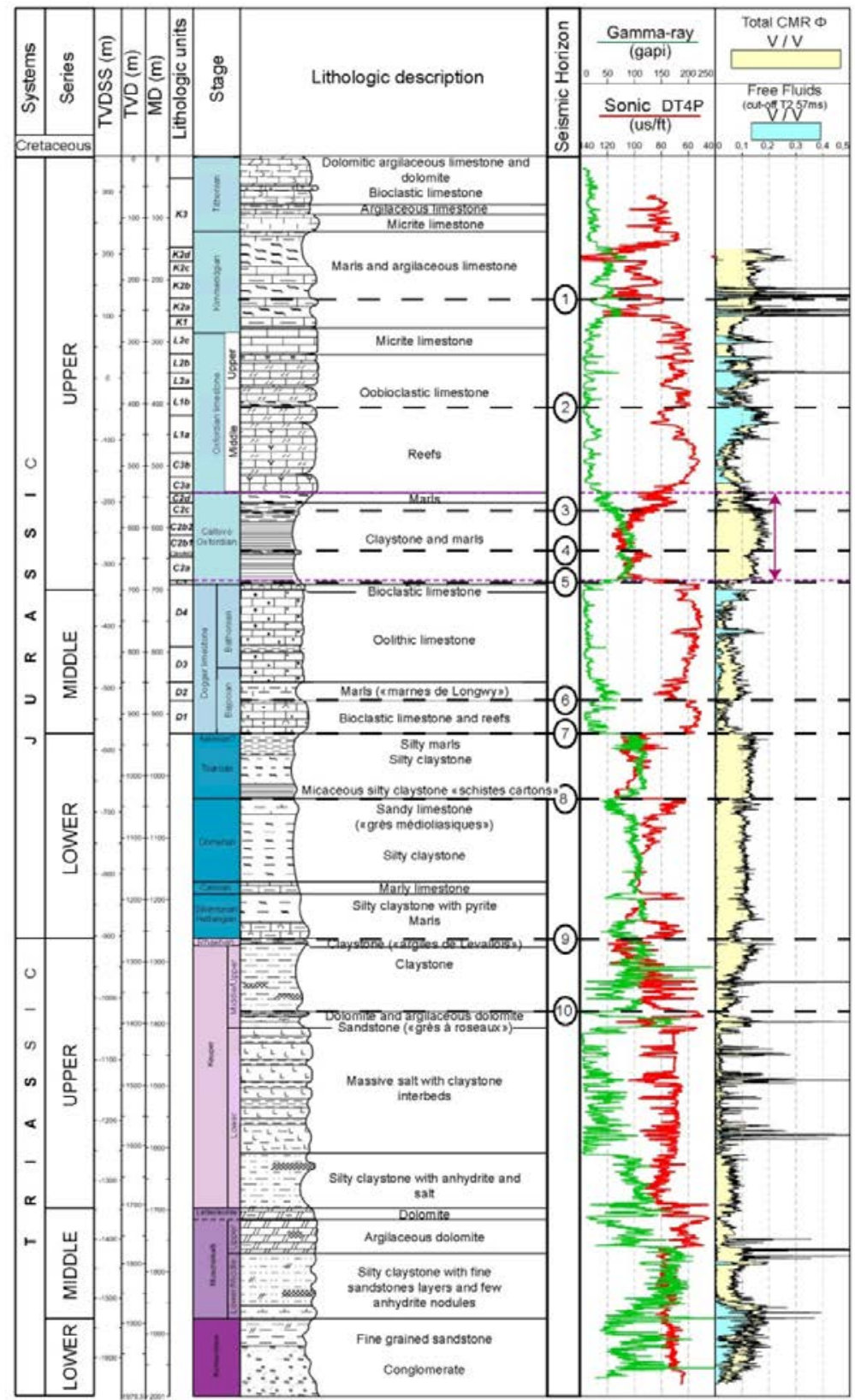

Figure 7.2 EST 433 geological log and seismic horizons. 1 Top of Kimmeridgian White Limestones, 2 Top of Porous Horizon HP4, 3 Top of Lower Oxfordian (nearly top of target interval), 4 Top of Upper Callovian (RIO), 5 Top of Carbonated Dogger (Base of target interval), 6 Base of Argillaceous limestones and marls, 7 Base of Carbonated Dogger, 8 Top of Domerian, 9 Base of Lias (base of Gryphees limestone), 10 Top of Beaumont dolomite. 
The deformations associated with tectonic plate movements have remained small for the past 150 million years, as in the rest of the Paris Basin (Guillocheau et al., 2000; Megnien, 1980). They are essentially limited to the Gondrecourt and Marne grabens, on the boundary of the sector studied (André et al., 2004; Rocher et al., 2004). The geological and geophysical studies have shown that the Cox layer is regular and virtually flat between these faults. Available data confirms that the region has very low seismicity.

\subsection{Seismic designs and processing sequence}

Figure 7.3 is a map showing the location of the 2D seismic line 07EST10 crossing the area covered by the 3D survey (in purple) and the location of 2 lines extracted from the 3D block: the in-line 405 (IL405) and the cross-line 217 (XL 217). Although there are no boreholes located in the 3D seismic survey area, additional $2 \mathrm{D}$ lines have been recorded to calibrate the 3D seismic data by tying to 3 wells (pink circles) situated outside of the 3D area. Line 07EST10 is an example of the additional 2D seismic lines. Well EST433 is located on the line 07EST10 in the vicinity of the CMP 654 (Common Midpoint).

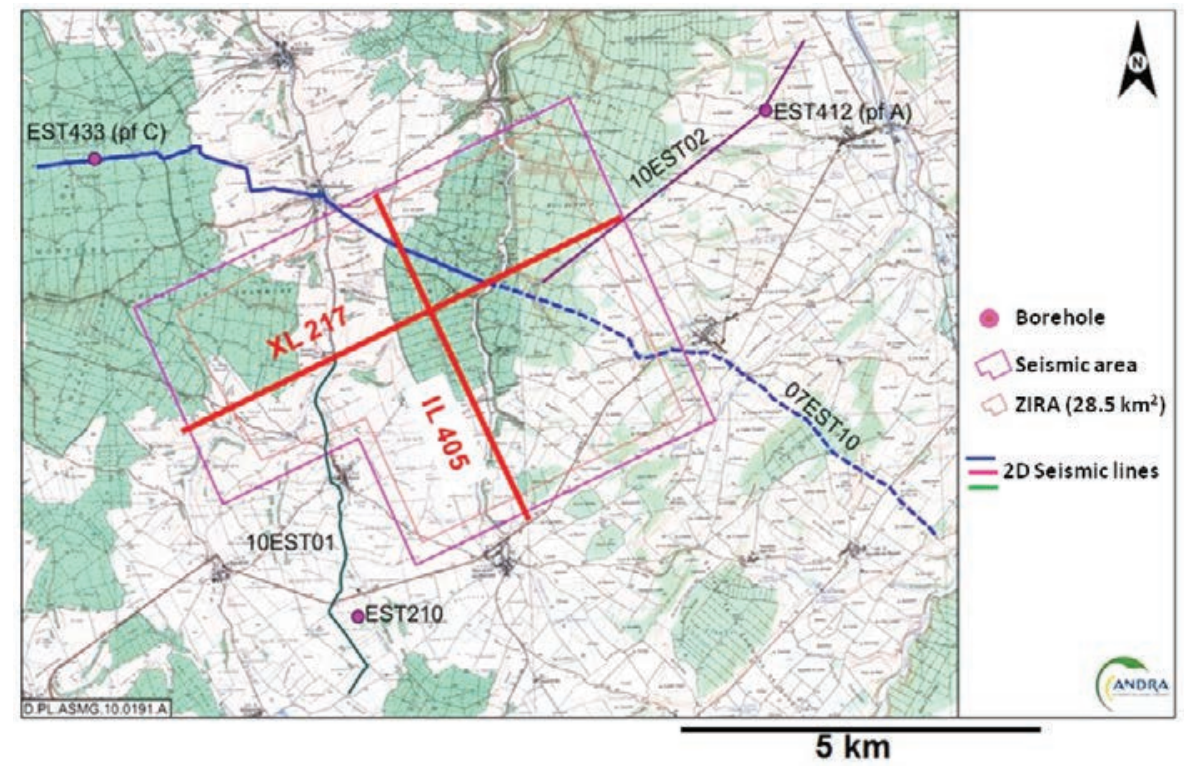

Figure 7.3 Seismic line implementation and well locations.

For the 3D seismic acquisition, the active spread (or template) is composed of 12 receiver lines with 120 stations on each line, with a cross-line roll along of 
6 receiver lines. The source lines are perpendicular to the receiver lines. The receiver and source line spacings are respectively $80 \mathrm{~m}$ and $120 \mathrm{~m}$. The receiver and source point spacings are $20 \mathrm{~m}$. The receiver is an array of 12 geophones. The length of the array equals the receiver interval $(20 \mathrm{~m})$. The source is a vibroseis source generating a signal in the $14-140 \mathrm{~Hz}$ frequency bandwidth. The bin size is $10 \times 10 \mathrm{~m}^{2}$. The nominal fold is 60 . The in-line IL 405 is composed of 544 CMP points. The crossline XL 217 is composed of 772 CMP points.

For the $2 \mathrm{D}$ seismic acquisition, the shot point is located at the centre of the receiver spread composed of 120 stations. The receiver and source point spacings are $25 \mathrm{~m}$. The source is a vibroseis source generating a signal in the $14-140 \mathrm{~Hz}$ frequency bandwidth. The bin size is $12.5 \mathrm{~m}$. The nominal fold is 60 . The selected part of the $2 \mathrm{D}$ line $07 \mathrm{EST} 10$ is composed of $727 \mathrm{CMP}$ points.

The main aim of the processing was to apply an amplitude preserving sequence and to accurately image the target zone. Frequencies above $100 \mathrm{~Hz}$ were also present in the final data volumes. Andra supplied a geological model (distribution of velocities in depth), which was used to compute a first set of static corrections (Figure 7.4). An up-hole survey consisting of 20 wells was used to calibrate the static correction model. The use of the statics model and a consistent processing approach for both the 2D seismic lines and the 3D seismic volume ensured a good match between them.

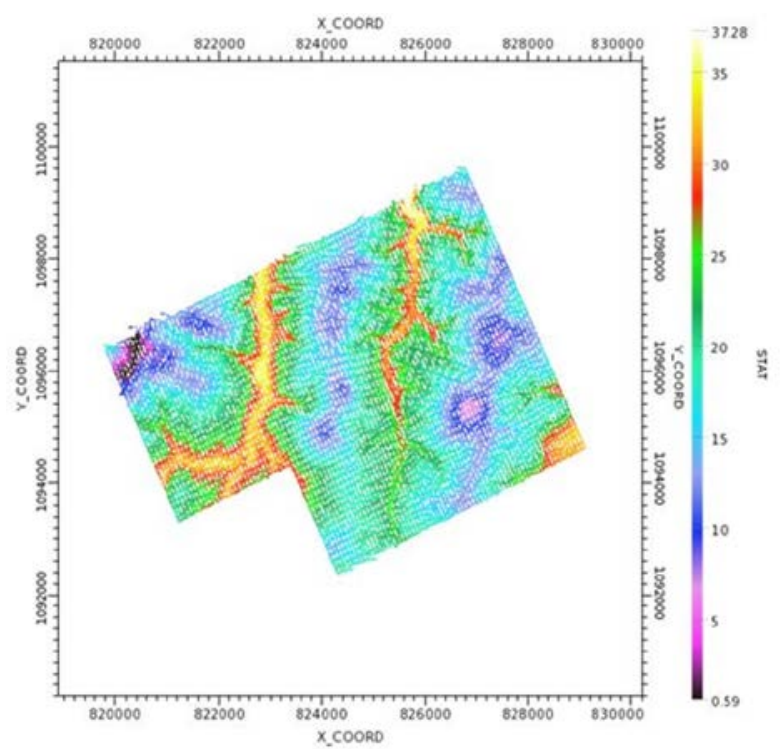

Figure 7.4 Map of basic static corrections (Andra document).

Although the area was generally rural, there were high levels of ambient noise, both linear and random. The $3 \mathrm{D}$ survey is located in forest and rural areas. In land seismic the variability of receivers is related to geophone coupling with the ground and 
to surface conditions. One of the main challenges of the processing was to effectively attenuate the noise and compensate source and receiver coupling as part of an amplitude preserving processing sequence. A methodical multi-domain approach, including shot, common offset and post stack domains, was used to analyse and apply suitable algorithms to progressively attenuate the observed noise. An iterative approach was seen to be the best method to optimize the noise attenuation and the compensation of source and receiver variability. The final pre-PSTM (Pre Stack Time Migration) sequence dedicated to noise attenuation and source-receiver variability compensation proved effective and achieved the aim of creating amplitudepreserved PSTM data.

The main seismic processing sequence steps were:

- data editing,

- minimum phase conversion,

- amplitude compensation (spherical divergence correction),

- surface consistent amplitude compensation (source and receiver),

- de-noise and wave separation on shots,

- statics application (data shifted to floating datum),

- surface consistent deconvolution,

- velocity analysis,

- surface consistent residual statics,

- second pass velocity analysis,

- surface consistent amplitude compensation (source, receiver and offset),

- interpolation and regularization in offset planes and noise attenuation,

- velocity model updating (residual move out),

- QC: 60 fold CMP stack (0-1,400 m offsets) with static to the final datum (450 m MSL),

- pre-stack time migration (time shifted to the final datum: $450 \mathrm{~m} \mathrm{MSL}$ ),

- Q compensation $(\mathrm{Q}=100)$,

- Noise attenuation and phase conversion (statistical to zero phase),

- Band pass filter $(15,20-140,160 \mathrm{~Hz})$.

However, using the processing sequence described, some undulations of the seismic horizons in time were observed on the obtained seismic lines. The undulations, which have no geological meaning, are characteristic of long wavelength static anomalies, which do not degrade the stack but can introduce structural anomalies. They are due to lateral variations in the properties of the weathering or shallow layers (elevation effects, lateral velocity variations, dip) which are negligible at the scale of the recording spread or CMP gather but not negligible at the scale of the seismic line. Short wavelength anomalies are detectable at the spread length and they degrade the CMP stack. They can be compensated for by the residual static correction methods.

In this area of the Paris Basin, the layer of the first 20 meters of variable velocity is the most sensitive layer of the static model. It largely conditions the shapes of 
seismic horizons and is the source of the long wavelength static anomalies. The velocities in the first $20 \mathrm{~m}$ are sensitive to:

- the nature of the formations affected by the alteration (Valanginian sands, Portlandian limestones or Kimmeridgian marls),

- the geomorphology (difference in velocities observed between plateaus, hillsides and valleys).

To compensate the long wavelength static anomalies, two procedures can be carried out:

- obtain a new set of static corrections based on refraction surveying (weathering shots) and up-hole surveying (VT: vertical times); including all the geological information available (geological maps). The seismic dataset must be completely reprocessed,

- estimate the geological time variation of the seismic horizons. The methodology is based on an a priori knowledge of the structural shape of the geological model. In 3D, a map of LWL static corrections has to be computed, the more appropriate method being a kriging method which allows the filtering of the map of the picked times of a reference horizon into a trend map and a residual map.
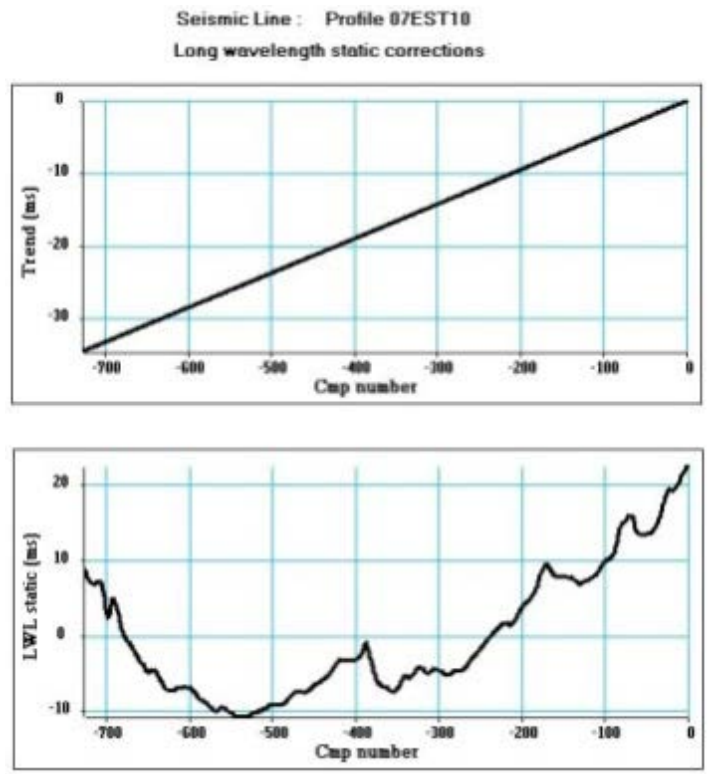

Figure 7.5 Long wavelength wave static correction - trend and LWL static curve.

To compensate the long wavelength anomalies, the picked times of major seismic horizons $(0.3-0.6 \mathrm{~s})$ have been considered as the stack of 2 functions: a trend which represents the geological time variation of the seismic horizon and a residual time function which represents the long wavelength anomaly correlated with 
the topographic variations of the floating DP. The residual time function is a long wavelength static correction which is applied on the post-stack migrated sections to compensate the long wavelength LWL static anomalies. Figure 7.5 shows the LWL static curve and the associated trend for the 2D line 07EST10. Figure 7.6 shows the 2D line 07EST10 before and after LWL static compensation.
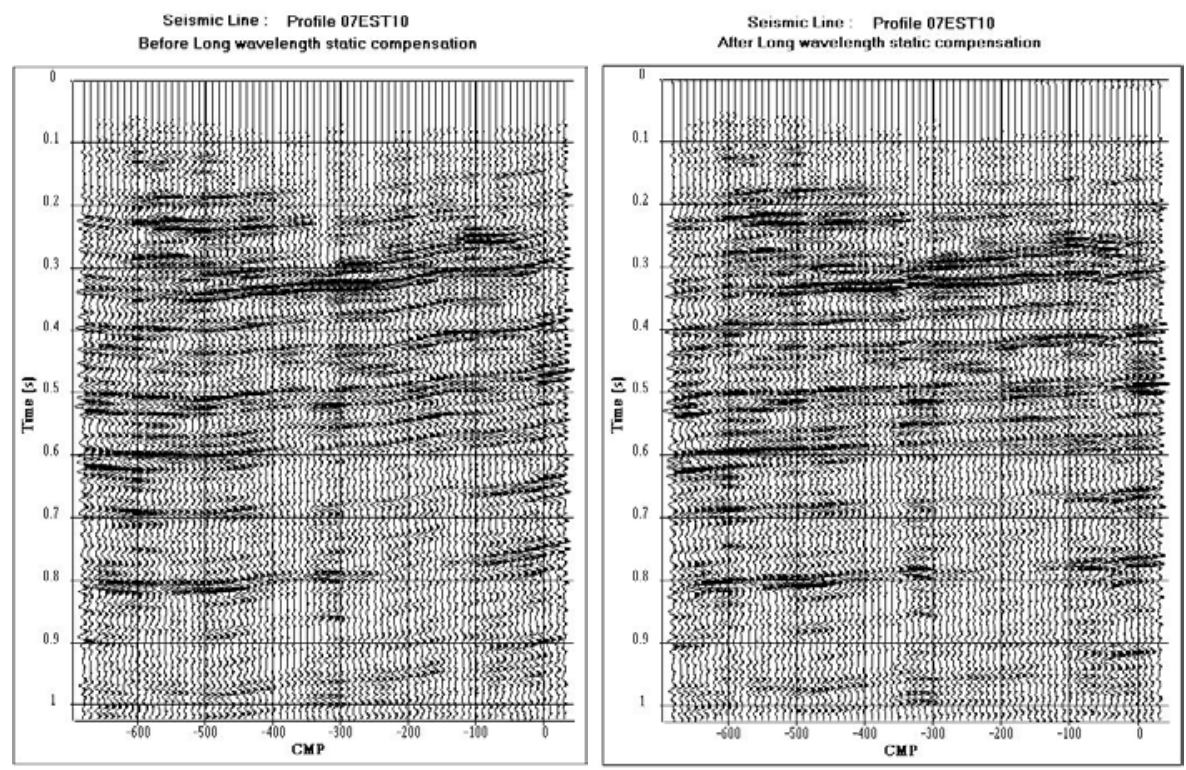

Figure 7.6 Long wavelength wave static compensation after stack. Left: seismic line before LWL static compensation. Right: seismic line after LWL static compensation.

During the migration process (Robein, 2003), the data are migrated and sorted into common image gathers (CIG) to update the velocity model before stacking. Each image gather is composed of migrated seismic traces which are functions of time (time migration) and offset or angle. The offset-angle conversion can be carried out during or after the migration process by using the velocity model. The common image gathers after offset-angle conversions are used to perform Amplitude versus Angle analysis (Castagna, 1993; Walden, 1991) and elastic inversion (EI). The small angle amplitudes (near-offset or intercept) migrated stacks relate to changes in acoustic impedance (AI) and can be inverted back to AI using a post-stack inversion algorithm (acoustic inversion). The acoustic impedance is a simple function of $\mathrm{P}$-wave velocity $\mathrm{Vp}$ and density $\rho(\mathrm{AI}=\rho . \mathrm{VP})$. The amplitudes of angle migrated stacks relate to changes in elastic impedance EI $(\theta)$. They can be inverted back to impedances $\mathrm{Ip}(\mathrm{Ip}=\mathrm{AI}=\rho . \mathrm{Vp})$ and Is (Is $=\rho . V s$ ) using a linearization of Zoeppritz equations for P-wave reflectivity $R(\theta)$. The reflectivity $R(\theta)$ is a function of the incidence angle $(\theta)$ and depends on the variations $\Delta V \mathrm{p}, \Delta \mathrm{Vs}, \Delta \rho$ of the mechanical parameters (Vp, Vs, $\rho$ ) of the two media located on each side of the discontinuity which generates the reflection. 
Shuey (1985) proposes the following approximation between the reflectivity $\mathrm{R}(\theta)$, the elastic impedance $\operatorname{EI}(\theta)$ and the mechanical parameters:

$$
R(\theta)=\frac{1}{2} \frac{\Delta \mathrm{EI}(\theta)}{\mathrm{EI}(\theta)}=A+B \sin ^{2}(\theta) \quad \text { with } \quad A=\frac{1}{2} \frac{\Delta \mathrm{Ip}}{\mathrm{Ip}}=\frac{1}{2}\left(\frac{\Delta \mathrm{Vp}}{\mathrm{Vp}}+\frac{\Delta \rho}{\rho}\right)
$$

The coefficient $\mathrm{B}$ is called the gradient and can be approximated by:

$$
B=\frac{1}{2}\left(\frac{\Delta \mathrm{Vp}}{\mathrm{Vp}}-\frac{\Delta \rho}{\rho}-2 \frac{\Delta \mathrm{V}_{\mathrm{s}}}{\mathrm{V}_{\mathrm{s}}}\right)
$$

The parameter $A$ in equation (7.1) represents the seismic trace as a compressional wave associated with acoustic impedance contrast Ip. The parameters $A$ and $B$ represent the seismic trace as a shear wave associated with acoustic impedance Is contrasts. If the incidence angle equals $0(\theta=0)$, the elastic impedance $\operatorname{EI}(\theta)$ is the acoustic impedance Ip. Equations (7.1) and (7.2) show that the elastic impedance $\operatorname{EI}(\theta)$ is a function of P-wave velocity $V p$, S-wave velocity $V s$, and density $\rho$. Connolly (1999) shows that the elastic impedance $\mathrm{EI}(\theta)$ can be written as follows:

$$
\mathrm{EI}(\theta)=\mathrm{Vp}^{\left(1+\tan ^{2} \theta\right)} \mathrm{Vs}^{-8 K \sin ^{2} \theta} \rho^{\left(1-4 K \sin ^{2} \theta\right)} \quad \text { with } \quad K=\frac{\mathrm{Vs}^{2}}{\mathrm{Vp}^{2}}
$$

Such processing is referred to elastic inversion (Shuey, 1985; Connolly, 1999; Whitecombe et al., 2002). A model-based elastic inversion (a priori impedance model obtained from well data), applied to the angle migrated stacks, provides impedance sections (Ip and Is sections). In our field case, three angle migrated stacks have been generated $\left(0-14^{\circ}, 14-28^{\circ}, 28-42^{\circ}\right)$ to perform the elastic inversion to compute Ip and Is - sections.
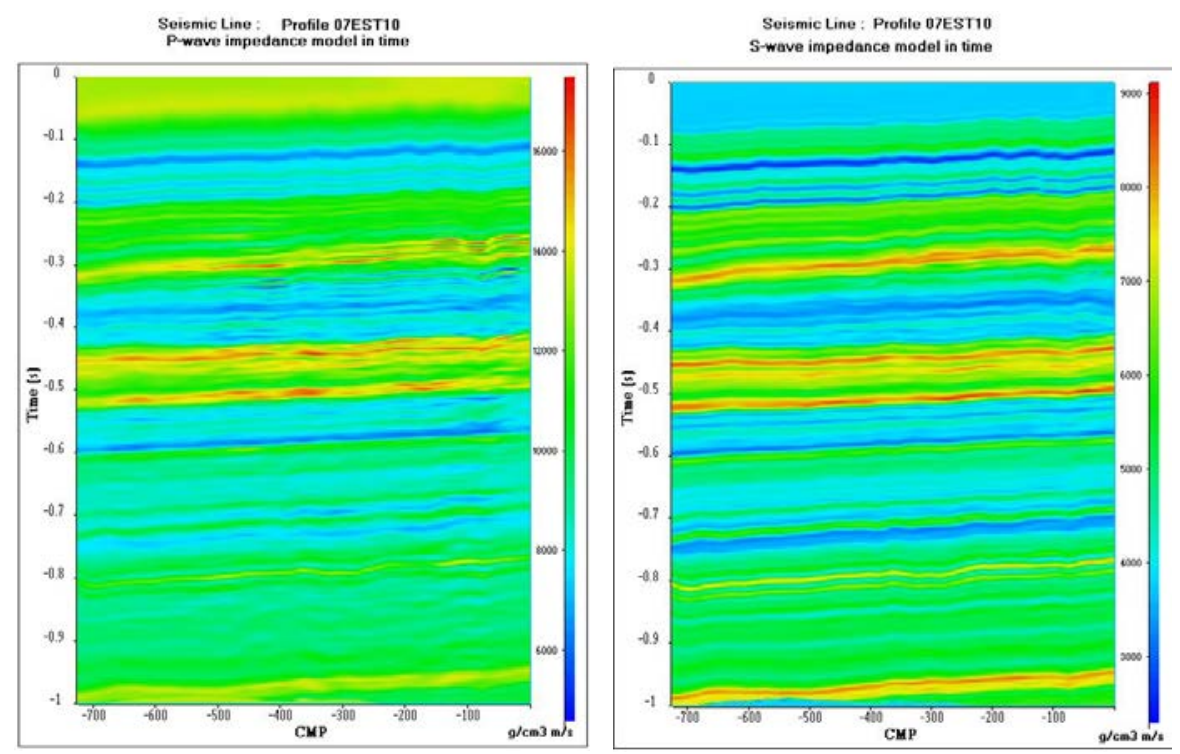

Figure 7.7 Ip and Is sections for the 07EST10 profile. 
Figure 7.7 shows the Ip and Is - sections associated with the 07EST10 profile.

Figures 7.8 and 7.9 show the results for the profiles extracted from the $3 \mathrm{D}$ block: IL405 and XL217. For each profile, we show the PSTM sections before and after LWL static compensation, the Ip and Is - sections.

Seismic Line : Profile IL405 before LWL Static corrections

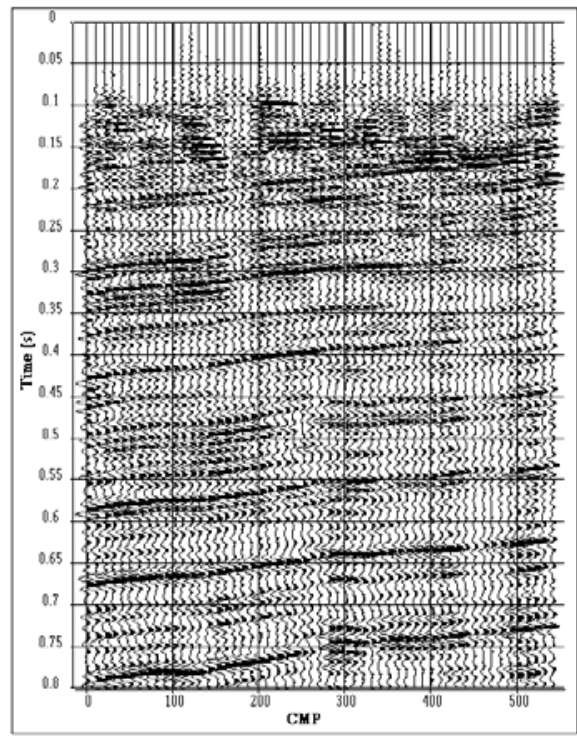

Seismic Line: Profile IL 405

P-wave impedance model in time

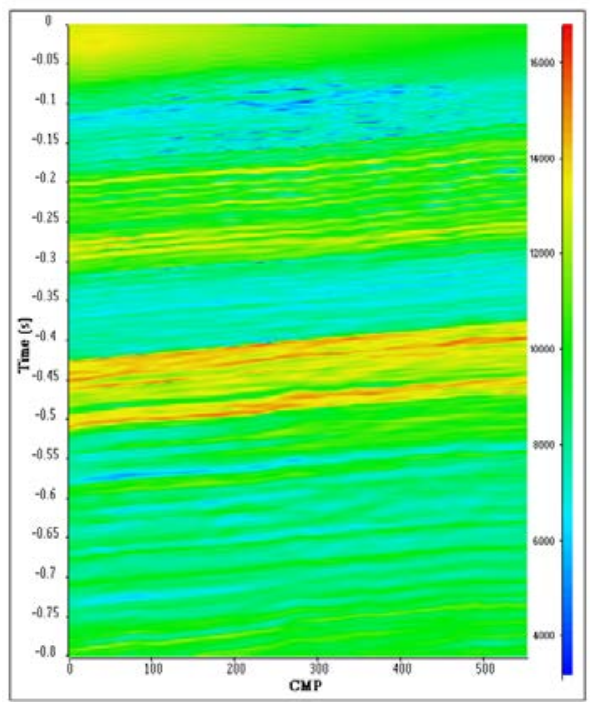

Seismic Line : Protile IL 405 after LWL. Static corrections

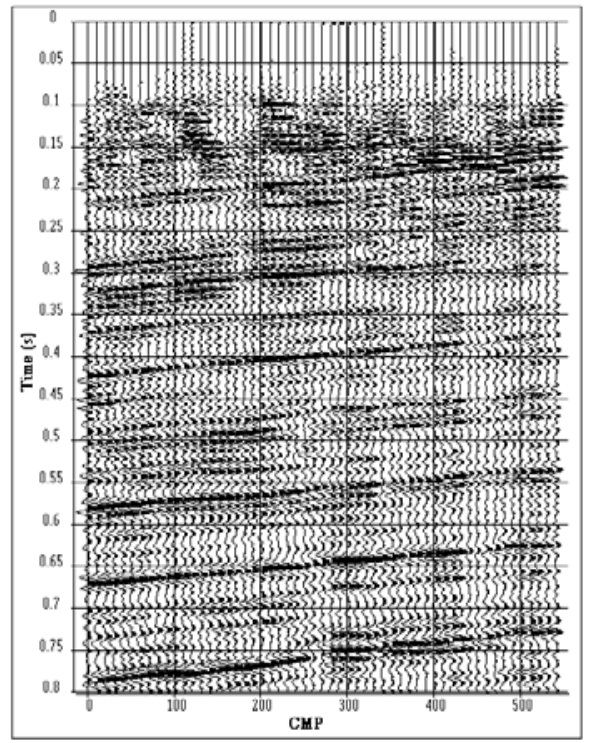

Seismic Line : Profile IL405

S-wave impedance model in time

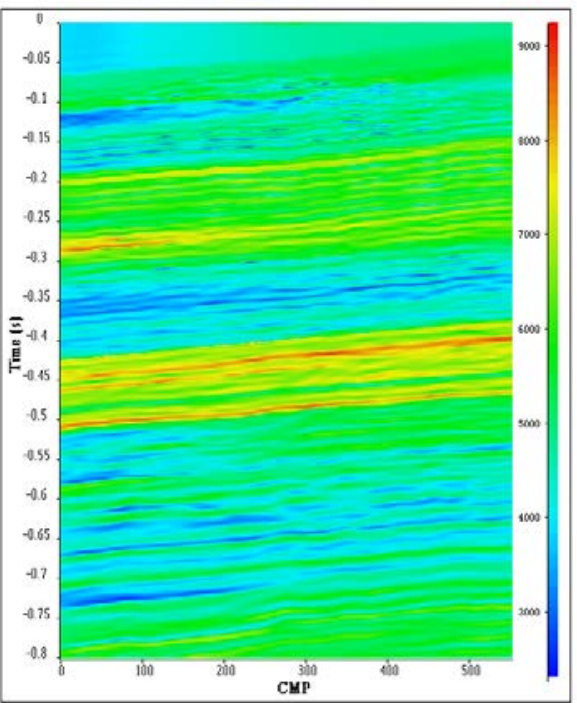

Figure 7.8 IL 405 profile. Top: PSTM sections before and after LWL static compensation. Bottom: Ip and Is sections. 
Seismic Line: Profile XL217 before LWL Static corrections

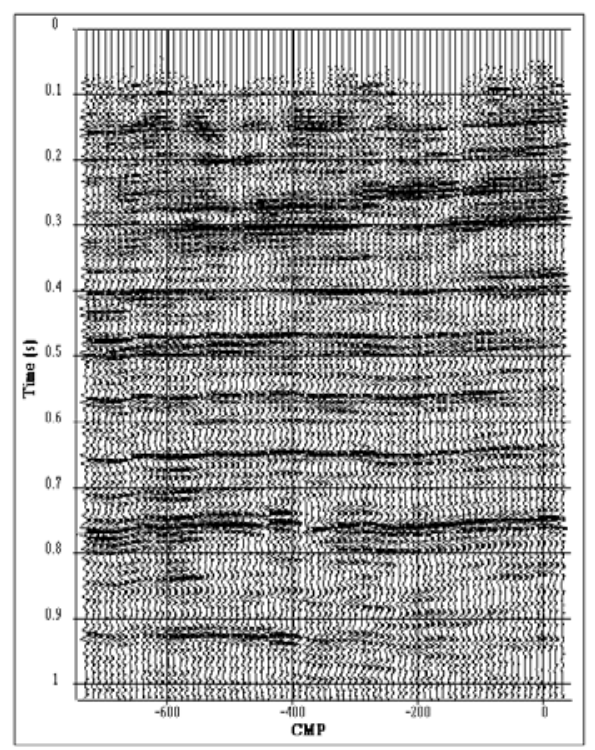

Seismic Line: Profile XL21?

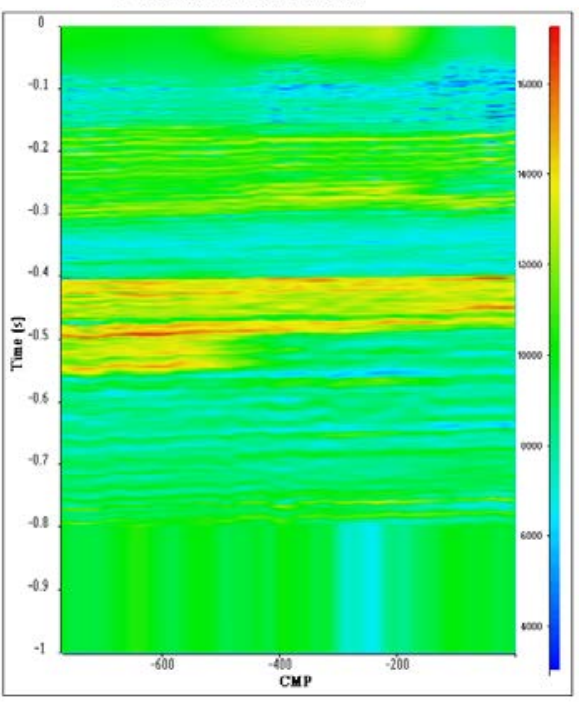

Seismic Line : Profile XL217 after LWL Static corrections

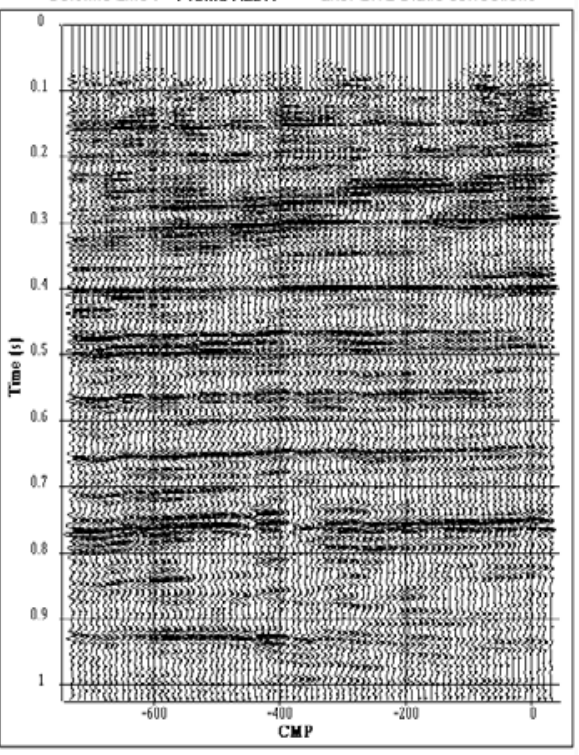

Seismic Line : Profite XL217

S-wave impedance model in time

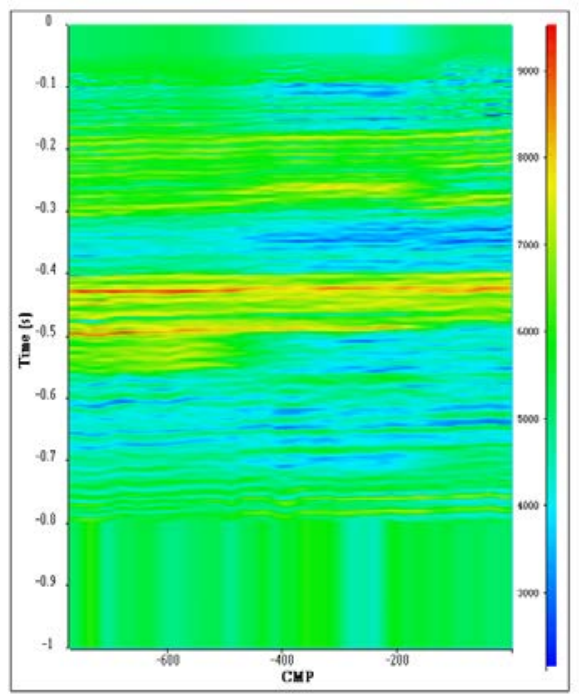

Figure 7.9 XL 217 profile. Top: PSTM sections before and after LWL static compensation. Bottom: Ip and Is sections. 


\subsection{Depth conversion}

A geostatistical approach for time-to-depth conversion of seismic horizons is often used in many geo-modelling projects. The more appropriate kriging method for this problem is the Bayesian Kriging method (Sandjivy and Shtuka, 2009). The Bayesian approach provides an excellent estimation, which is more general than the traditional kriging with external $\operatorname{drift}(\mathrm{s})$ and fits very well with the requirements for time-to-depth conversion of seismic horizons. For each selected horizon, Bayesian Kriging (BK) provides its estimated depth $\mathrm{Z}$ associated with its time $\mathrm{t}$, in agreement with all the calibration points (well tops depth...). BK depth conversion also provides the underlying interval velocity model (trend and residual), and associated quantified uncertainties. The BK depth conversion simultaneously updates the estimated depths of all the seismic horizons.

Figure 7.10 illustrates the time-to-depth conversion of seismic horizons by the BK method, using the UDOMORE depth software developed by Seisquare. The advantage of using the Bayesian Kriging (BK) for estimations compared to other approaches is that we can simultaneously manage the uncertainty on the trend velocity model and the local uncertainty defined by the uncertainty of interpreted time maps and local fluctuations of interval velocities.

The input information required for BK consists of:

- two-way-time (TWT) maps for interpreted horizons,

- well markers for each horizon,

- prior velocity model and associated uncertainty for each layer,

- local uncertainty definition for each time map (picking uncertainty, and spatial variogram definition),

- local uncertainty definition of interval velocity for each layer (local velocity fluctuations around the trend model, and spatial variogram definition).

Like any kriging-based estimation approach, the Bayesian Kriging (BK) provides:

- the estimated variable (estimated depth for each horizon),

- variance of estimation (associated uncertainty of estimated depth).

The advantage of using $\mathrm{BK}$ in depth conversion is that it provides the ability to combine the prior knowledge of the velocity model with a certain degree of uncertainty and the well data. All sources of uncertainty (velocity and time) are integrated in a consistent way in a unique probabilistic model used for estimation or simulation.

For each selected horizon, the Bayesian Kriging provides its estimated depth $\mathrm{Z}$ associated with its time $t$. The " $Z$ versus $t$ " data set is interpolated in the whole space (3D block) at the time sampling rate $(1 \mathrm{~ms})$ to obtain a time-to-depth conversion model, using the impedance sections to estimate the short wavelength variations of the velocity model. 
The time-to-depth conversion procedure is illustrated via the line XL 217 (see location map, Figure 7.3). Ten seismic horizons, numbered 1 to 10, have been picked in time and converted to depth. The 10 seismic horizons are:

1. Top of Kimmeridgian White Limestones

2. Top of Porous Horizon HP4

3. Top of Lower Oxfordian (close to the top of target interval)

4. Top of Upper Callovian (RIO)

5. Top of Carbonated Dogger (base of target interval)

6. Base of Argillaceous limestone and marls

7. Base of Carbonated Dogger

8. Top of Domerian

9. Base of Lias (base of Gryphees limestone)

10. Top of Beaumont dolomite

Figure 7.10 shows the picked times of the 10 seismic horizons (left) and the depth conversion of the 10 horizons (right).

Profile XL 217 : Seismic Horizons in time

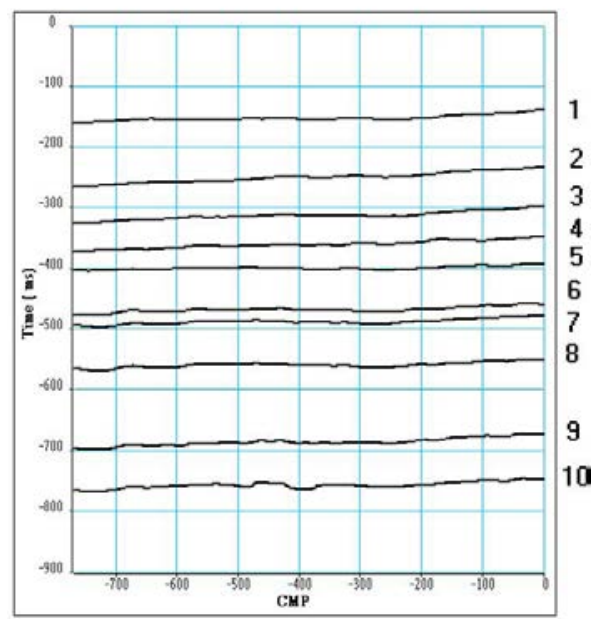

Profile X1 217: Seismic Horizons in depth (Bayesian Kriqging)

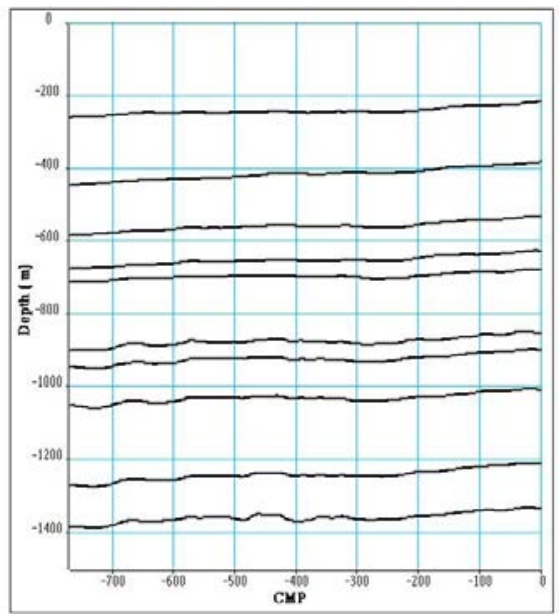

Figure 7.10 Time-to-Depth of seismic horizons by Bayesian Kriging. Example of the XL 217 profile (left: horizon in time, right: horizons in depth).

To obtain a high-resolution velocity model, the acoustic impedance Ip obtained by inversion can be used assuming that the $\mathrm{P}$-wave velocity and the density of a formation vary in a consistent way (an increase of velocity is associated with an increase of 
density) and a relationship between the two variables exists. The Gardner's relation (Gardner et al., 1974) given by the following equation $\rho=\alpha \mathrm{Vp}^{\beta}$ is often used.

The logging data (sonic and density logs) recorded at well Est433 (see map location, Figure 7.3) have been used to compare acoustic impedance $I p$ and velocity $V p$ logs and the relationship given by equation (7.4) has been checked:

$$
\log (\mathrm{Vp})=\operatorname{Av} \cdot \log (\mathrm{Ip})+\mathrm{Bv}
$$

The coefficients $\mathrm{Av}$ and $\mathrm{Bv}$ have been computed in a root mean square sense, between the $\mathrm{Vp}$ and Ip logs. The results of the minimization have shown that the Vp $\log$ and the predicted P-wave velocity from the acoustic impedance log are strongly correlated (Figure 7.11, left). The correlation coefficient and the Taner-Kohler coefficients between the two velocity logs are very high $(>0.98)$ and a single law can be used whatever the range of acoustic impedance and whatever the geological unit to obtain a high-resolution velocity model in time $\mathrm{Vp}$ given by equation (7.4). Consequently a density log can be easily obtained by the ratio Ip to Vp.

The velocity model was integrated in time to obtain a time-depth conversion model (Figure 7.11, right). The time-depth conversion model was used to convert in depth any type of time-seismic sections such as amplitude, instantaneous frequency, Ip and Is, and consequently $\mathrm{Vp}$, Vs and density.

Well Est433

Predicted P-wave velocity (VPimp) from acoustic impedance Imp

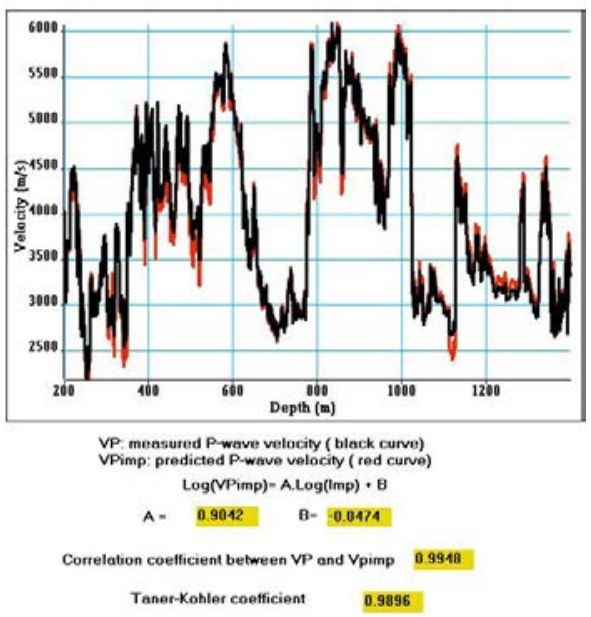

Seismic Line: Protile 07EST10

Time to depth conversion law

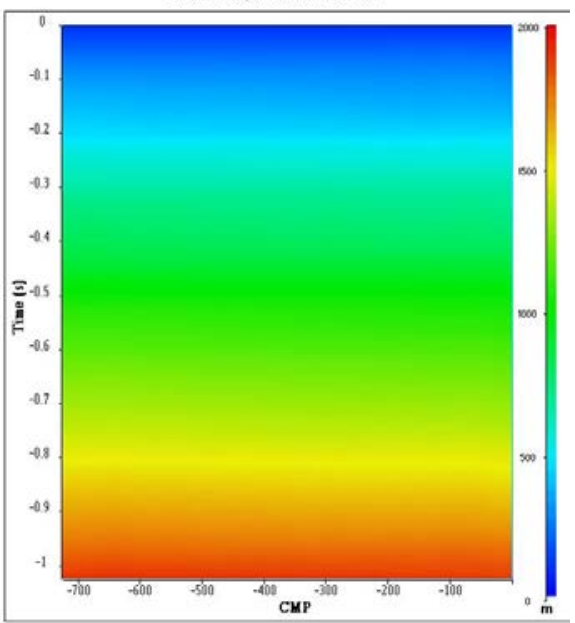

Figure 7.11 Predicted P-wave velocity model and time-to-depth conversion model. 
The depth conversion is not calibrated in depth. This must be carried out, and it can be performed using the depth conversion of seismic horizons by a geo-statistical method (Omre H. 1987, Sandjivy L. and Shtuka A. 2009) which simultaneously uses Bayesian co-kriging and a multilayer model, and which handles the following sources of uncertainty:

1. Velocity model uncertainty: this relates to regional (trend or low frequency) uncertainty and local uncertainty (high frequency velocity fluctuations that are invisible on the seismic).

2. Time interpretation uncertainty. Even when one considers that interpretation is unbiased and calibrated, there are fluctuations that cannot be observed by the seismic because of limited resolution.

3. Well marker uncertainty.

The depth converted horizons are calibration points for the velocity model extracted from the acoustic impedance distribution. The updated velocity model thus obtained must be consistent with an underlying interval velocity model obtained by the geostatistical method for the time-to-depth conversion of seismic horizons with a resolution comparable to the resolution of the acoustic impedance sections. Some results have already been obtained using seismic lines extracted from the 3D seismic survey recorded on the Zira area (Mari J.L. and Yven B., 2014).

The P-wave velocity distribution $V p$ and the results of elastic inversion $I p(I p=A I$ $=\rho . V p)$ and $I s(I s=\rho . V s)$ are used both to compute the shear wave velocity $V s$ and the density $\rho$ distributions in depth. The values of densities obtained are realistic for the sedimentary layers present. They vary between 2.25 and $2.70 \mathrm{~g} / \mathrm{cm}^{3}$. In the Callovo-Oxfordian, the highest value of the density is $2.48 \mathrm{~g} / \mathrm{cm}^{3}$.

Figures 7.12 to 7.14 show the results obtained for the 3 profiles: 07EST10, IL405, XL217. For each profile, we show the seismic line after depth conversion, the distribution of P-wave and S-wave velocities in depth, and the distribution of density in depth. 

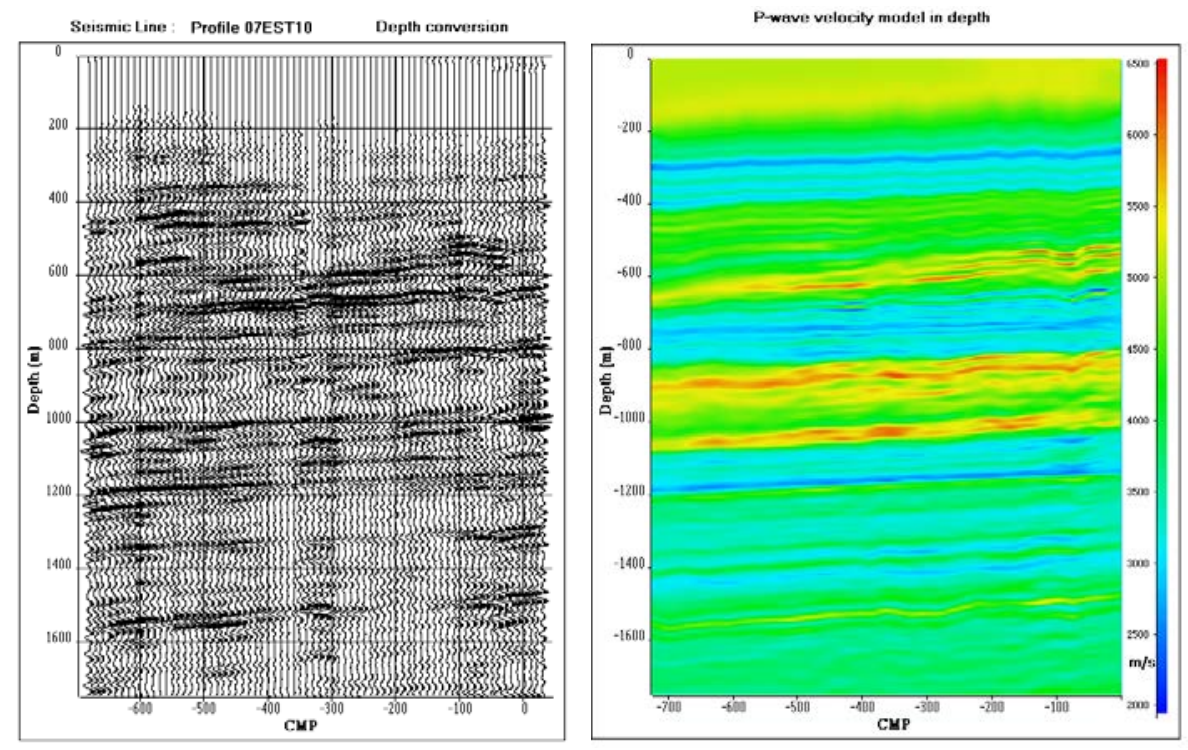

S-wave velocity model in depth
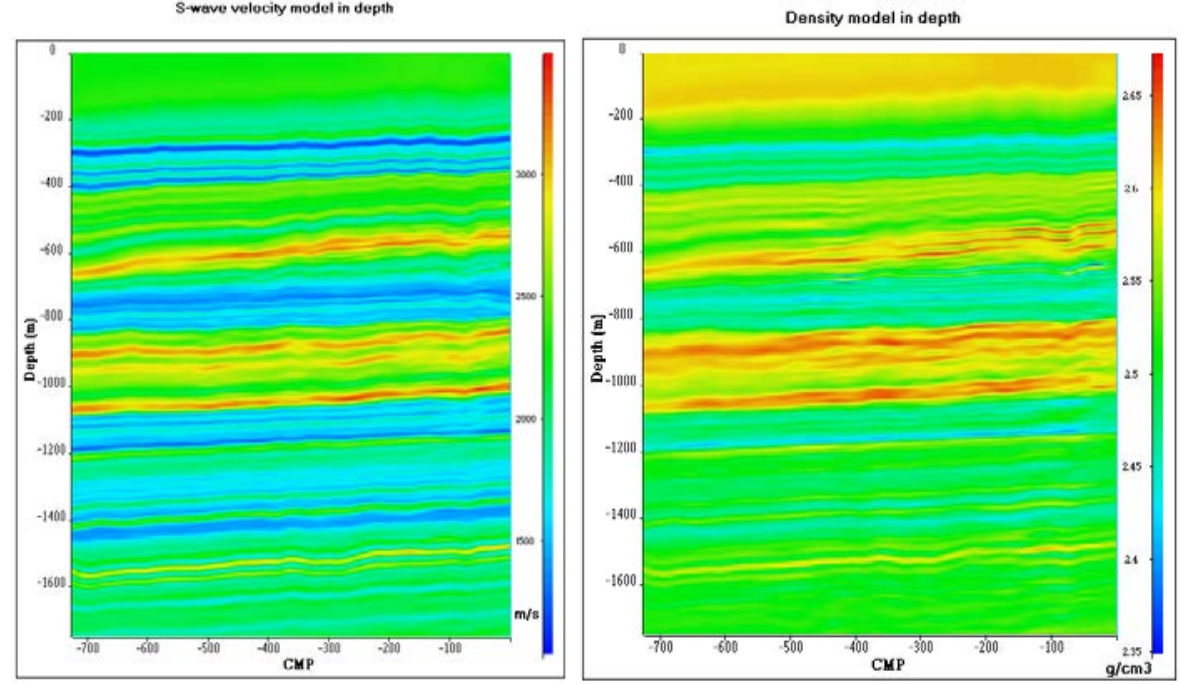

Figure 7.12 Profile 07EST10. Top: section in depth and P-wave velocity distribution in depth, Bottom: S-wave velocity and density distributions in depth. 

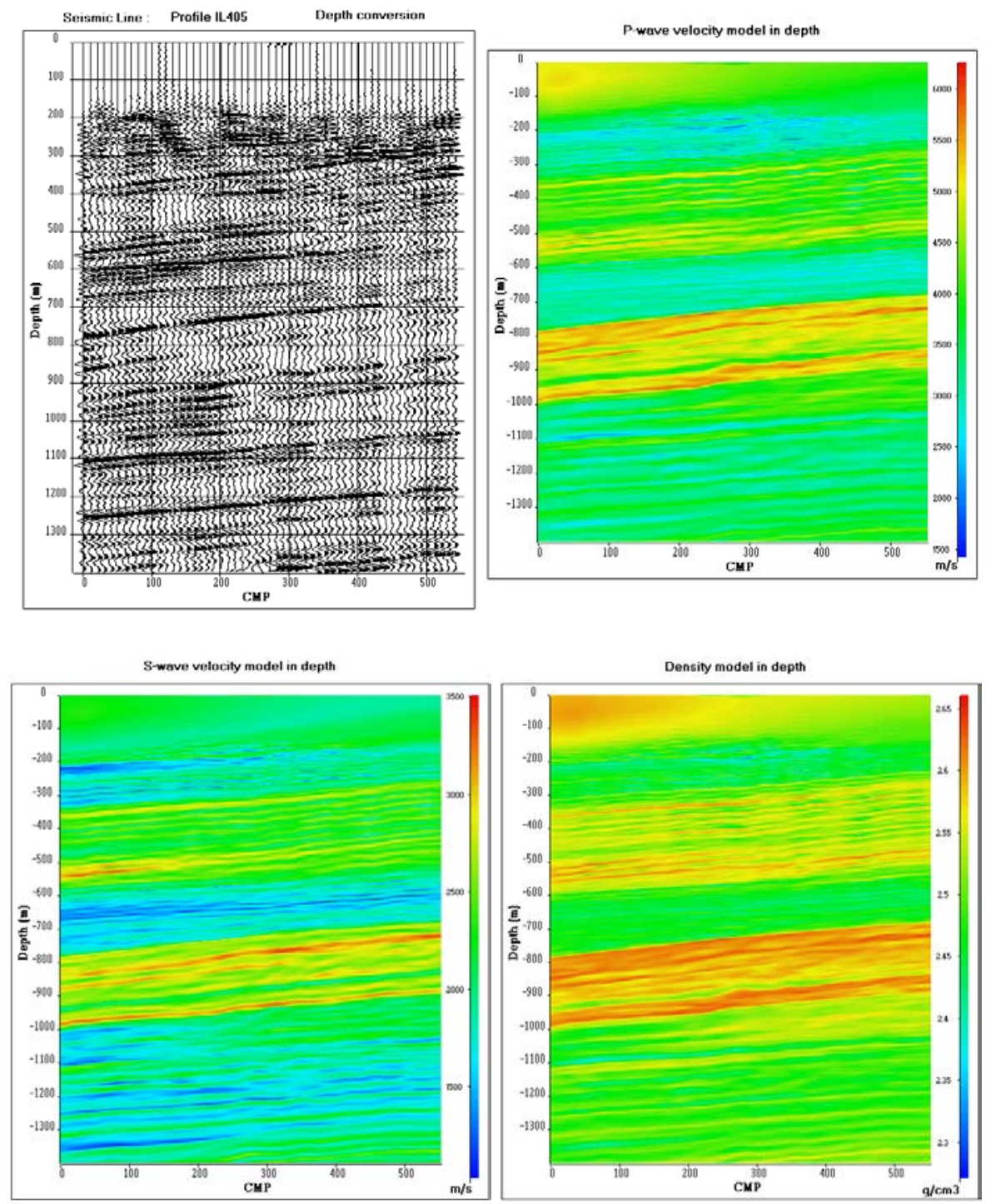

Figure 7.13 Profile IL405. Top: section in depth and P-wave velocity distribution in depth; Bottom: S-wave velocity and density distributions in depth. 
Seismic Line : Profile X1217 Depth conversion

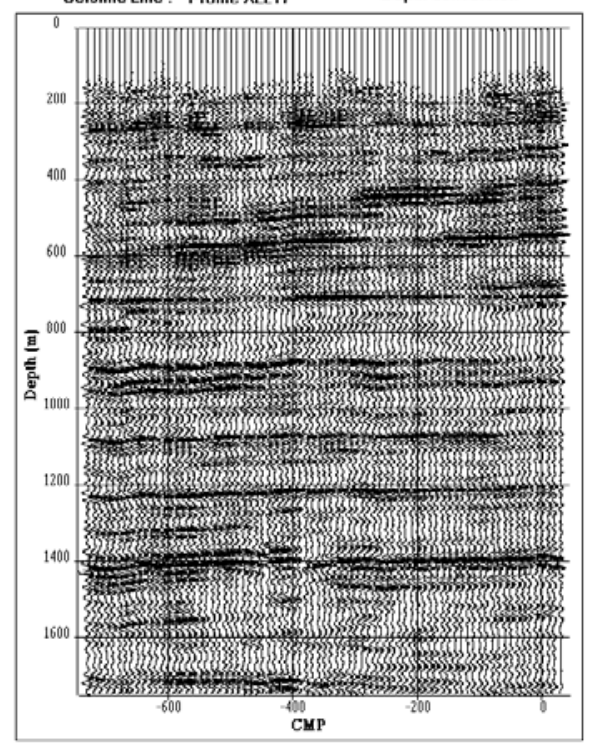

S wave velocity model in depth

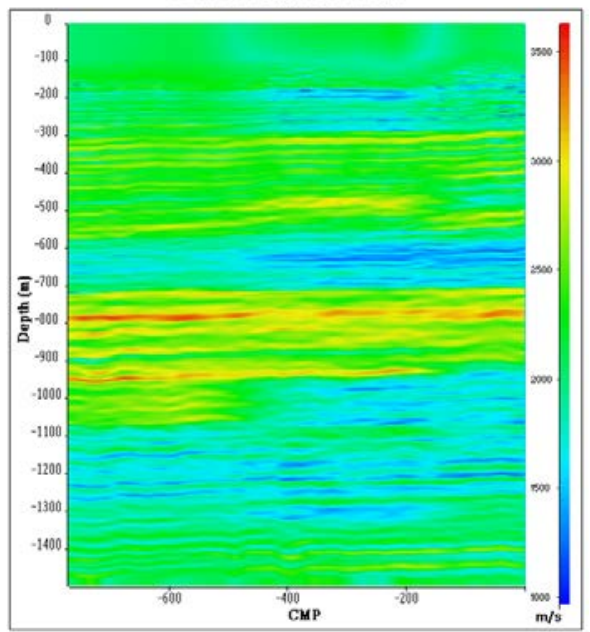

P-wave velocity model in depth

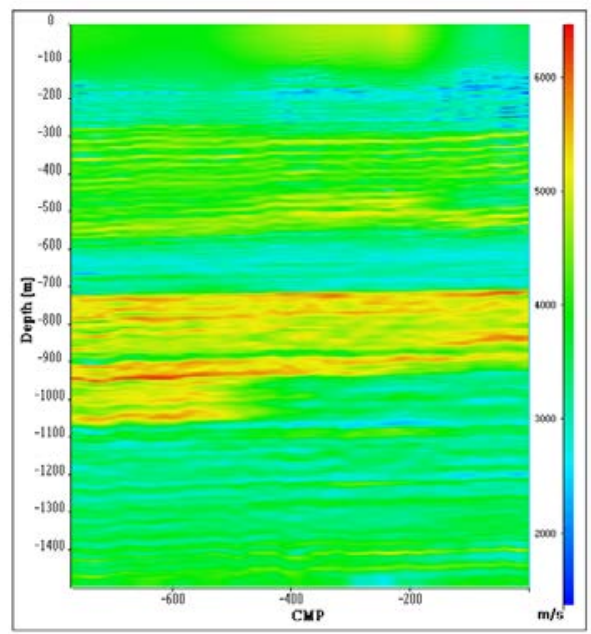

Density model in depth

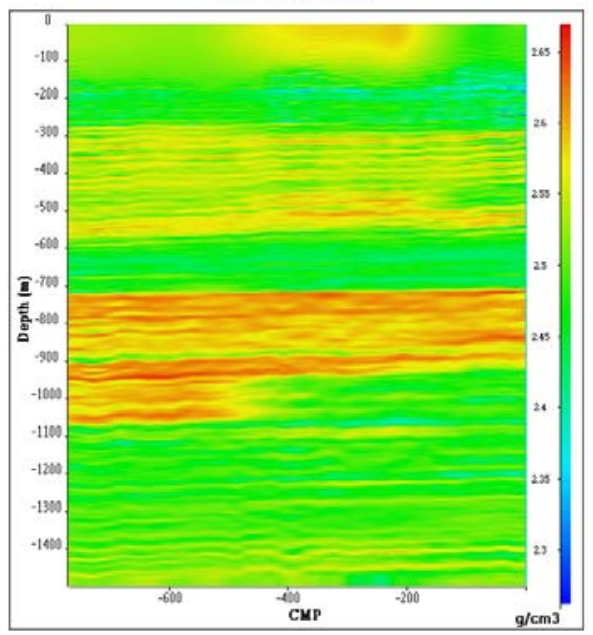

Figure 7.14 Profile XL217. Top: section in depth and P-wave velocity distribution in depth; Bottom: S-wave velocity and density distributions in depth. 


\subsection{Amplitude quality control}

A Stochastic Quality Assessment (SQA) workflow has been designed to assess the reliability of the stacked amplitudes and to optimize further modelling of mechanical and hydrogeological properties.

3D line $\times 2.217$ : Instantaneous Amplitude in depth

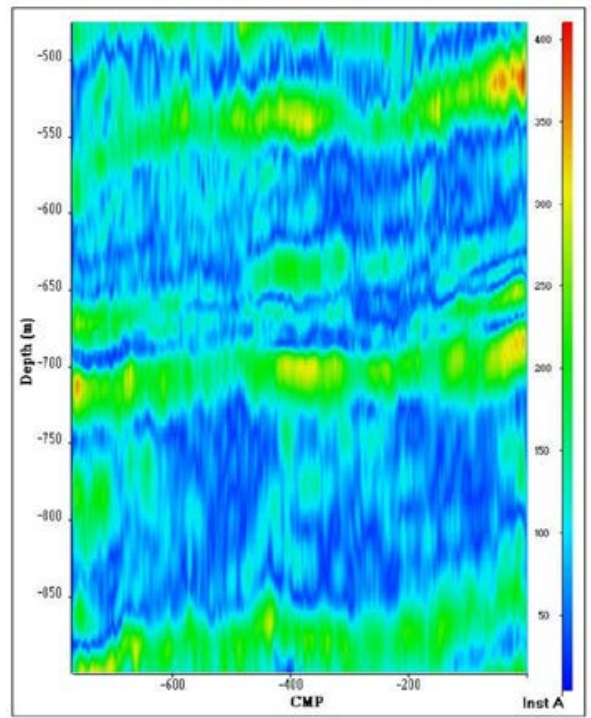

30 line $\mathrm{XL217}$ : SOl factor in depth

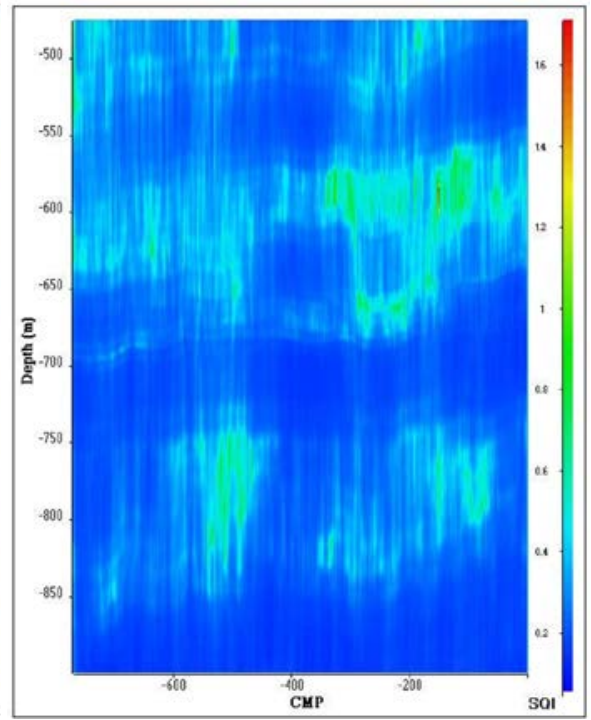

Figure 7.15 Profile XL217. Instantaneous amplitude (left) and SQI factor (right).

SQA processing of seismic data works under a mathematical framework known as geostatistics, where the observed (measured) seismic amplitude is considered as a realization of a random function (RF) defined in space and time (Shtuka et al., 2011 and 2009). The added value of using this type of theoretical framework is that it takes into account the spatial correlation between measured seismic amplitudes at different locations using variogram or spatial covariance. Interpretation and modelling of the experimental variogram computed in the offset direction (for fixed time) on pre-stack gather data enables the assessment of the signal and noise content of the seismic measurements in terms of the contributive (signal) and noncontributive (noise) part of the stacking process. The signal/noise interpretation of the variogram is quantified by modelling the experimental variogram accordingly in both horizontal (offset or angle) and vertical (time) directions. SQA handles the global non-stationary behaviour of the gather, by relying only on a local stationarity assumption: local computations and modelling of variogram parameters (sill and ranges) are performed inside a local neighbourhood defined around each sample 
location. The variogram model is used to compute the estimated variance of the stacked trace of the gather as the variance of the estimation error: unknown "true" stacked amplitude minus estimated stacked amplitude. The estimation variance is normalized and expressed as a percentage of the stacked amplitude called the Spatial Quality Index (SQI). Low SQI values mean good confidence in the stacked amplitude.

The results shown here were obtained on the XL217 cross-line on the seismic cube (Figure 7.3). Figure 7.15 shows the instantaneous amplitude section (left) and its associated SQI factor (right). The sections are shown in depth. The time-to-depth conversion is discussed later. The quality of seismic instantaneous amplitudes is quantified by their attached SQI values. Blue SQI areas on the seismic section (low SQI values) indicate reliable amplitudes (80 to $90 \%$ reliability), green SQI areas indicate less reliable amplitudes (50 to $70 \%$ reliability). The more significant processes were analysed in greater detail, confirming that the amplitudes were not adversely affected by the processing.

\subsection{Q factor}

We present here the methodology developed to estimate the Q factor per layer, using VSP data. It shows how the procedure has been extended to estimate the Q factor of seismic lines.

A number of discussions in the literature use different approaches, which lead to a general form for the frequency dependence of the phase velocity. A synthesis has been carried out by Valera (1993). The resulting expression, which is valid for a relatively large and constant $\mathrm{Q}$, is given by:

$$
V\left(f_{1}\right) / V\left(f_{2}\right)=1+(1 / \pi Q) \cdot \operatorname{Ln}\left(f_{1} / f_{2}\right)
$$

Where $\mathrm{Q}$ is the constant $\mathrm{Q}$ factor, $\mathrm{V}\left(\mathrm{f}_{1}\right)$ is the propagation velocity at frequency $f_{1}$, $V\left(f_{2}\right)$ is the propagation velocity at frequency $f_{2}$.

Equation (7.5) can be written as follows:

$$
Q=(1 / \pi) \cdot(V / \Delta V) \cdot \operatorname{Ln}\left(f_{1} / f_{2}\right)
$$

Where $\Delta V=V\left(f_{1}\right)-V\left(f_{2}\right)=\Delta z / \Delta t-\Delta z /(\Delta t+d \Delta t)$ and $V=\Delta z /(\Delta t+d \Delta t)$ $=V\left(f_{2}\right)$

Equation (7.5) shows that the high frequency components of a wave train propagate faster than the low frequency components.

For a VSP, Q is computed from equation (7.6). For 2 geophone positions ( $\Delta z$ apart), $\Delta V$ is estimated from the variation $\Delta t$ of the arrival times of the down-going wave over a distance $\Delta z$ and from $d \Delta t$ the residual variation of $\Delta t$ due to the variation of frequency between $f_{1}$ and $f_{2}$. 
Figure 7.16 (top left) shows a VSP recorded in well Est 433 (Figure 7.3) as well as its frequency-wavenumber (f-k) diagram. It is composed of 221 levels, with a depth sampling of $5 \mathrm{~m}$ between 112 and $687 \mathrm{~m}$, and a depth sampling of $10 \mathrm{~m}$ between 687 and $1,737 \mathrm{~m}$. The source is a vibrator (sweep 14-140 Hz). The time sampling is $1 \mathrm{~ms}$ and the recording length is $2 \mathrm{~s}$ after correlation. The down-going and up-going waves have been separated by $\mathrm{f}-\mathrm{k}$ filtering. To obtain an estimate of the $\mathrm{Q}$ factor per layer, we used the fact that attenuation introduces dissipative dispersion, which can be measured from the frequency-dependent phase velocity of the VSP down-going wave (equation (7.6)). The picked times of the first pick of the first arrival have been used to compute the velocity log versus depth, and to measure the frequency log from the instantaneous frequency VSP section, using the analytic signal computed by the Hilbert transform. The 2 logs are shown in Figure 7.16 (top right). The down-going waves have been filtered with a low frequency band $(8-28 \mathrm{~Hz})$. The average value of the instantaneous frequency $f_{2}$ of the filtered down-going wave is $21.5 \mathrm{~Hz}$ and the associated standard deviation is $2 \mathrm{~Hz}$. A scan procedure in $d \Delta t$, equivalent to a velocity scan, was implemented to estimate the quantity $\Delta \mathrm{V}$ and the $\mathrm{Q}$ factor (equation (7.6)), the search carried out in a realistic $Q$ value domain, such as between 20 and 100 (Mari and Yven, 2018). If the $f_{1} / f_{2}$ ratio is close to a constant, the $\mathrm{V} / \Delta \mathrm{V}$ ratio is a linear function of $\mathrm{Q}$. For $\mathrm{Q}$ ranging from 20 to 100 , the $\mathrm{V} / \Delta \mathrm{V}$ ratio varies from 50 to 250 for an $f_{1} / f_{2}$ ratio of 3.5 (Figure 7.16, bottom left).

Figure 7.16 (bottom left) shows, from top to bottom: the V/ $\Delta \mathrm{V}$ curve for an $f_{1} / f_{2}$ ratio of 3.5; the $d \Delta t, \Delta V$ and $V / \Delta V$ curves versus the level of the borehole geophone. The average value of the $\Delta V$ curve is $27 \mathrm{~m} / \mathrm{s}$ and its associated standard deviation is $4 \mathrm{~m} / \mathrm{s}$. Figure 7.16 (bottom right, black curve) shows the computed Q factor log. $\mathrm{Q}$ values vary between 33 and 96 . Due to standard deviation low values of the $\Delta V$ curve $(4 \mathrm{~m} / \mathrm{s})$ and of the $f_{2}$ frequency curve $(2 \mathrm{~Hz})$, the $\mathrm{Q}$ factors can be predicted using constant values for $\Delta V$ and $f_{2}$. The predicted Q-factor curve is shown in Figure 7.16 (bottom right, red curve) as well as the associated relative uncertainty (10\% on average) between the 2 Q-logs. The correlation coefficient between the 2 Q-logs is high (0.94). The correlation coefficient between Q factors and interval velocities is 0.69 . The $\mathrm{Q}$ factor of the $\operatorname{Cox}(550-700 \mathrm{~m})$ is estimated at 40 , while the $\mathrm{Q}$ factors of the Oxfordian and Dogger limestone located directly above and below are higher, ranging from 65 to 90 .

The results have been validated on a second well, Est 412 (Figure 7.17), the predicted $\mathrm{Q}$ values being estimated from the law defined at well Est 433. The uncertainties between the 2 Q-logs are weak, ranging between 0.5 to $30 \%$. Consequently, the predicted Q $\log$ can be applied to surface seismic data if interval velocities $V\left(f_{1}\right)$ and instantaneous frequencies $f_{1}$ are measured. 

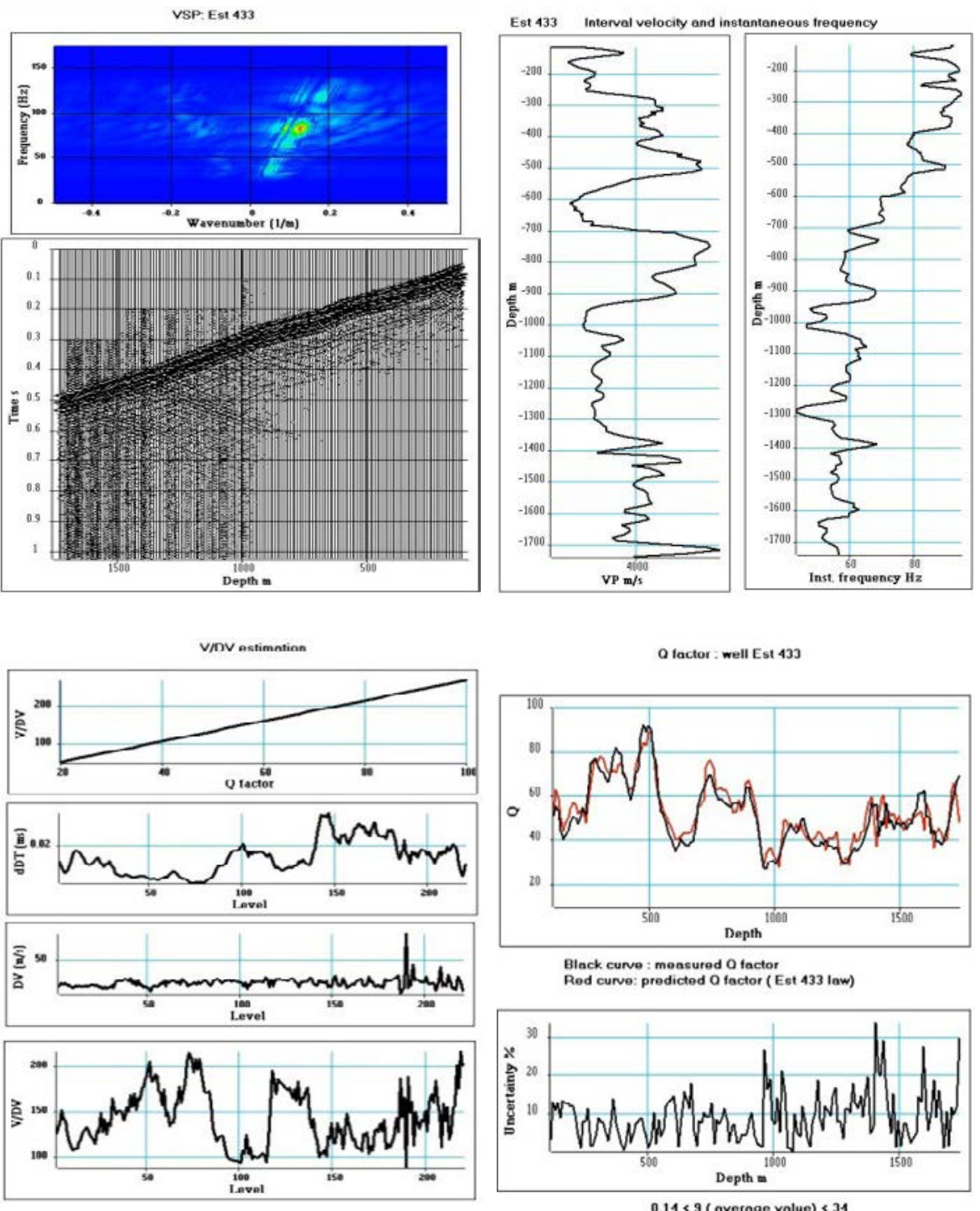

Figure 7.16 VSP and Q factor at well Est 433. Top left: VSP and its associated f-k diagram; Top right: Velocity $(V(f 1))$ and frequency (f1) logs. Bottom left: VIAV estimation: Bottom right: Q factors (measured, predicted) and uncertainties. 

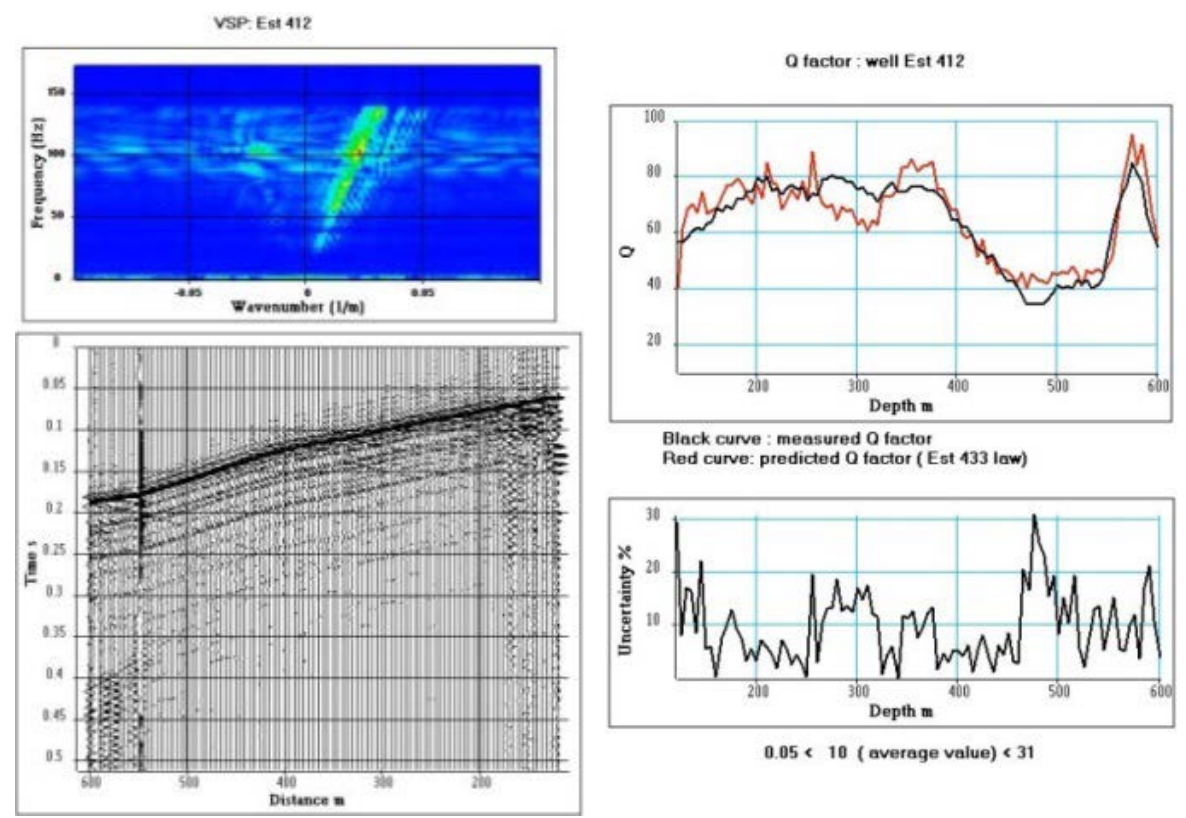

Black curve : measured $Q$ factor

Red curve: predicted $Q$ factor (Est 433 law)

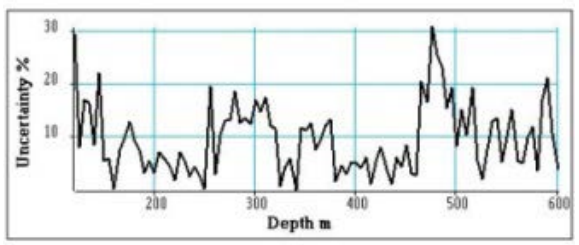

$0.05<10$ (average value) $<31$

Figure 7.17 VSP and Q factors with uncertainties at well Est 412.

For each seismic line in time, the instantaneous frequency section has been computed by analytic signal (Hilbert transform), and then depth converted. The distributions in depth of the instantaneous frequencies and P-wave velocities (Figures 7.12 to 7.14) have been used to predict the distribution of the Q-factor in depth, using equation (7.6) with the constant values for $\Delta \mathrm{V}$ and $f_{2}$ given by the VSP analysis carried out at well Est 433.

The instantaneous frequency section and the Q-factor distribution for the line 07 EST10 are shown in Figure 7.18 (top). Figure 7.18 (bottom) also shows the Q-factor distributions for the lines IL405 and XL 217. 

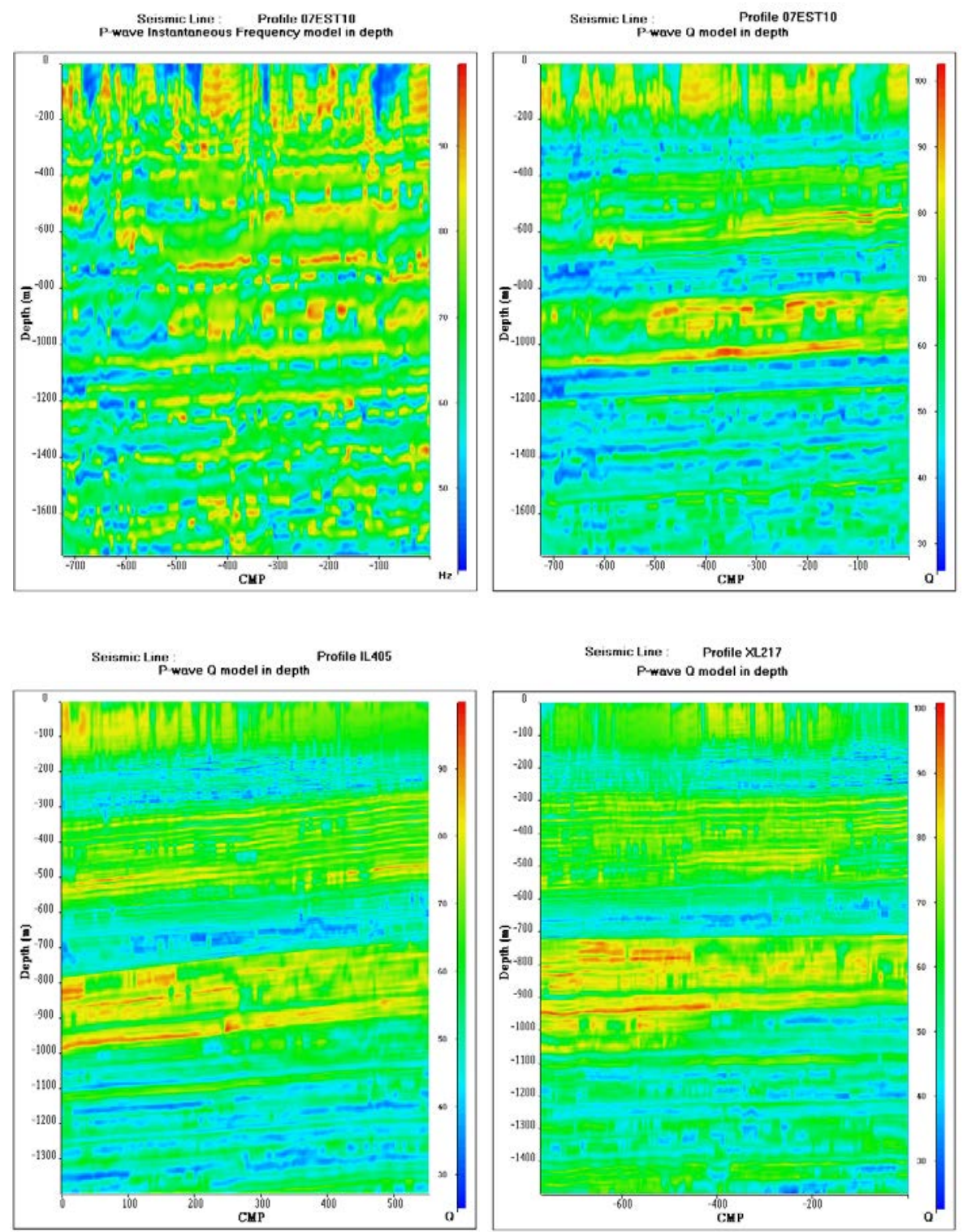

Figure 7.18 Q models in depth. Top: Profile 07EST10. Instantaneous frequency and Q model. Bottom: Profiles IL405 and XL217. Q models. 


\subsection{Mechanical properties}

To prepare for the construction and operation of a deep geological disposal facility, the mechanical behaviour of the rock formations must be well understood. One of the parameters studied for this purpose is the Young's modulus. A workflow has been developed to estimate static Young's moduli in claystone and limestone formations on seismic lines.

The P-wave and S-wave velocity $(\mathrm{Vp}, \mathrm{Vs})$ distributions and the density $\rho_{\text {bulk }}$ distribution obtained by elastic inversion of the seismic data after calibration on well data (VSP and acoustic logs) enable the computation of dynamic mechanical modules, such as the shear modulus $(\mu)$, Young's modulus (E), Poisson's ratio $(v)$. The dynamic Young's modulus is given by the following formula (equation (7.7)):

$$
\begin{gathered}
E=\rho_{b u l k} V_{\mathrm{P}}^{2} \frac{(1-2 v)(1+v)}{(1-v)}, \\
v=\frac{\left(V_{\mathrm{P}} / V_{\mathrm{S}}\right)^{2}-2}{2\left[\left(V_{\mathrm{P}} / V_{\mathrm{S}}\right)^{2}-1\right]}=\frac{V_{\mathrm{P}}^{2}-2 V_{\mathrm{S}}^{2}}{2\left(V_{\mathrm{P}}^{2}-V_{\mathrm{S}}^{2}\right)}
\end{gathered}
$$

The Vp, Vs and $\rho_{\text {bulk }}$ distributions for the seismic lines 07EST10, IL405 and XL217 are shown in Figures 7.12 to 7.14 respectively.

Mechanical properties of the Callovo-Oxfordian clay formation were characterized in the laboratory (deformation modulus, compressive strength, tensile strength, etc.) using conventional triaxial or uniaxial compression tests. Samples that were significantly desaturated $(\mathrm{Sr}<90 \%)$ or damaged were eliminated from the analysis. Finally 39 core samples, selected from the Cox in well Est 433, were used to measure the static Young's moduli ES in the laboratory. At the same depths, logging data (acoustic and density logs) were used to compute the dynamic Young's moduli ED. The results are shown in Figure 7.19 (top left).

A description of methods for determining the relationship between static and dynamic Young's moduli can be found in a number of standard texts. A synthesis is given by Eissa and Kassi (1988). In the laboratory it has been shown that it is possible to predict the static moduli values ES from the dynamic values ED. The appropriate function relating to the high correlation coefficient between measured and predicted static values is the linear function:

$$
\mathrm{ES}=\mathrm{a} \cdot \mathrm{ED}+\mathrm{b}
$$

However, Eissa and Kassi (1988) have shown that the value of the static modulus of elasticity can be best predicted from the relationship:

$$
\log _{10}(E S)=a \cdot \log _{10}\left(\rho_{\text {bulk }} E D\right)+b
$$


Equation (7.9) has been used to compute the static Young's modulus using logging data (dynamic modulus computed by equation (7.7)) and core data (static modulus obtained in the laboratory). The coefficients "a" and "b" are evaluated to obtain an optimum fit between the static modulus from core data with the predicted static modulus from logging data (Yven and Mari, 2018). Figure 7.19 (bottom left) shows the static Young's moduli from the laboratory (blue crosses), the dynamic Young's from logs (black crosses), and the predicted static Young's moduli (red crosses). Figure 7.19 (right) shows the associated histograms.

From Dynamic to Static Young modulus
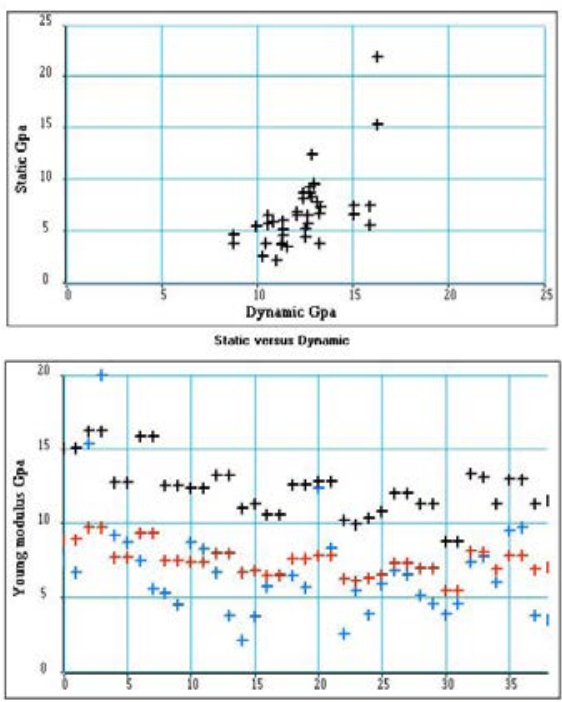

Dlack etoss: Dynamic Young modulua [ logging] , blue crosx: Static Young modulua [coee ] Red ctoss: Oynamic to Static Young modulus:
From Dynamic to Static Young modulus: Histograms
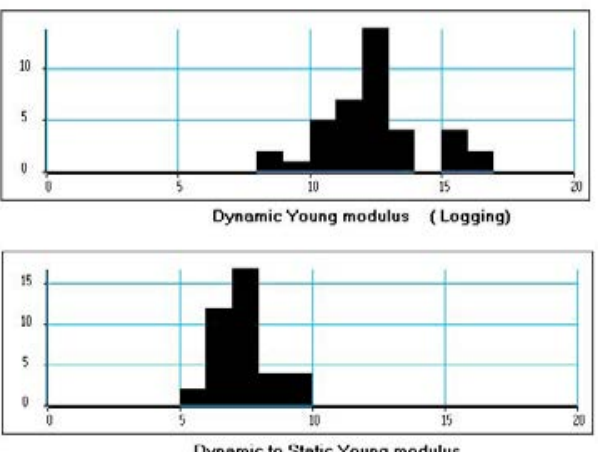

Dynamic to Static Young modulus

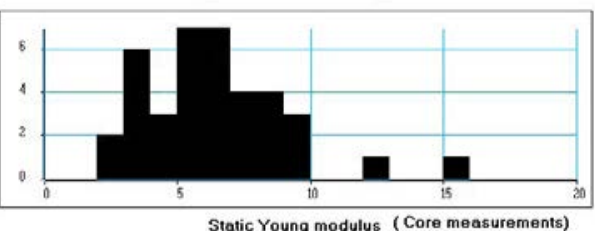

Figure 7.19 From dynamic to static moduli. Left: static Young's moduli from laboratory (blue crosses), the dynamic Young's moduli from logs (black crosses), and the predicted static Young's moduli (red crosses). Right: histograms.

Figures 7.20 to 7.22 show the results obtained on the seismic profiles 10EST10, IL405 and XL217 respectively. For each seismic line, we show the distribution of dynamic Young's moduli in depth computed from the Vp, Vs and density distributions obtained by elastic inversion and depth conversion, the distribution of static Young's moduli in depth given by equation (7.9), the static to dynamic ratio distribution in depth, and the histograms of the two sets of moduli. The Static to Dynamic Young's modulus ratio varies between 0.49 to 0.58 . The static to dynamic conversion has been carried out with cores from the Cox. In future, the relationship between static and dynamic will be analysed with other boreholes, per each geological unit. 

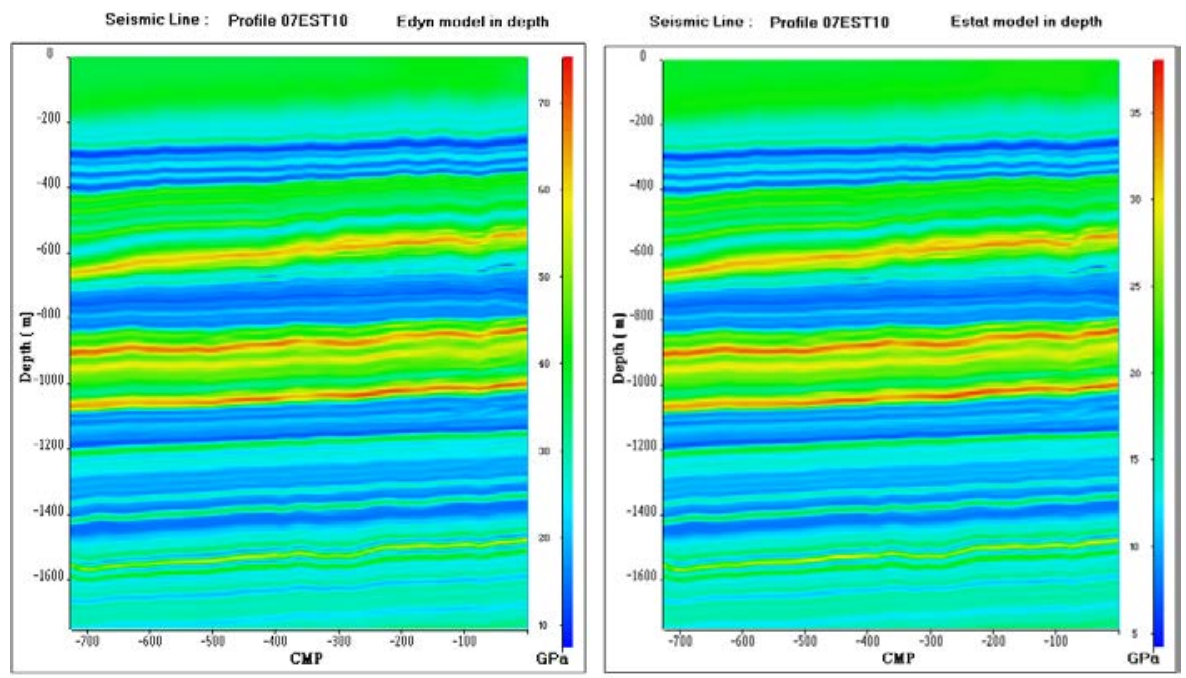

Seismic Line: Profile 07EST10 Estat to Edyn ratio in depth

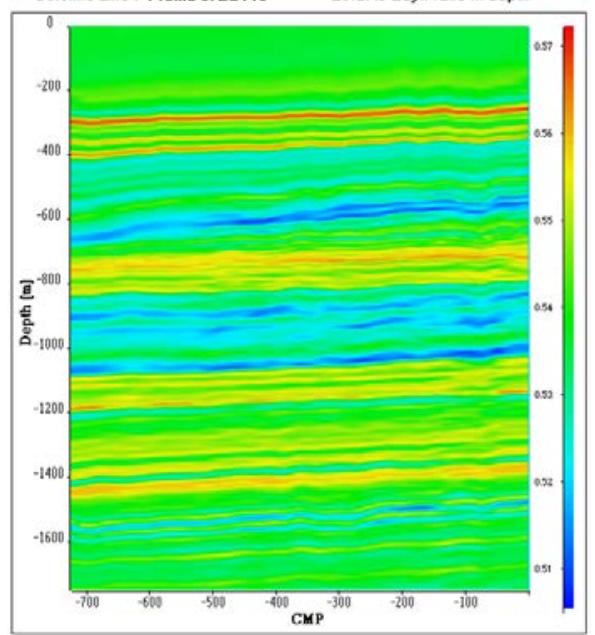

Seismic Line : Profile 07EST10

His:toģrams

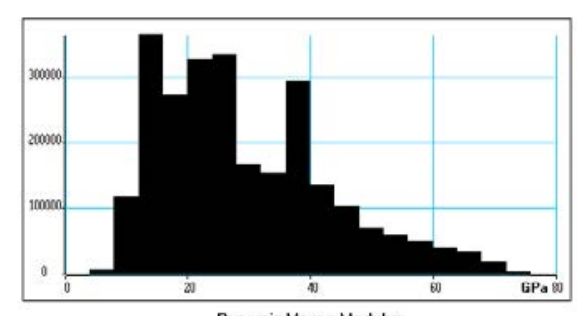

Dynamic Young Modulus

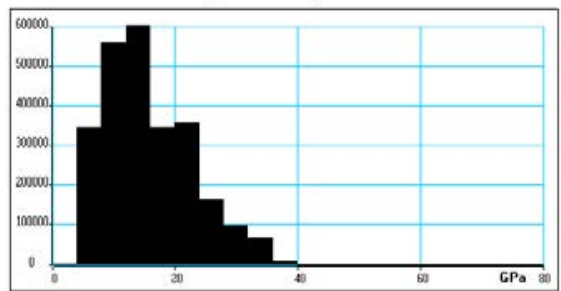

Figure 7.20 Seismic line 07EST10 - From dynamic to static moduli. Top: distribution of dynamic (left) and static (right) Young's moduli in depth. Bottom: Static to dynamic ratio in depth (left), Histograms of dynamic and static Young's moduli. 

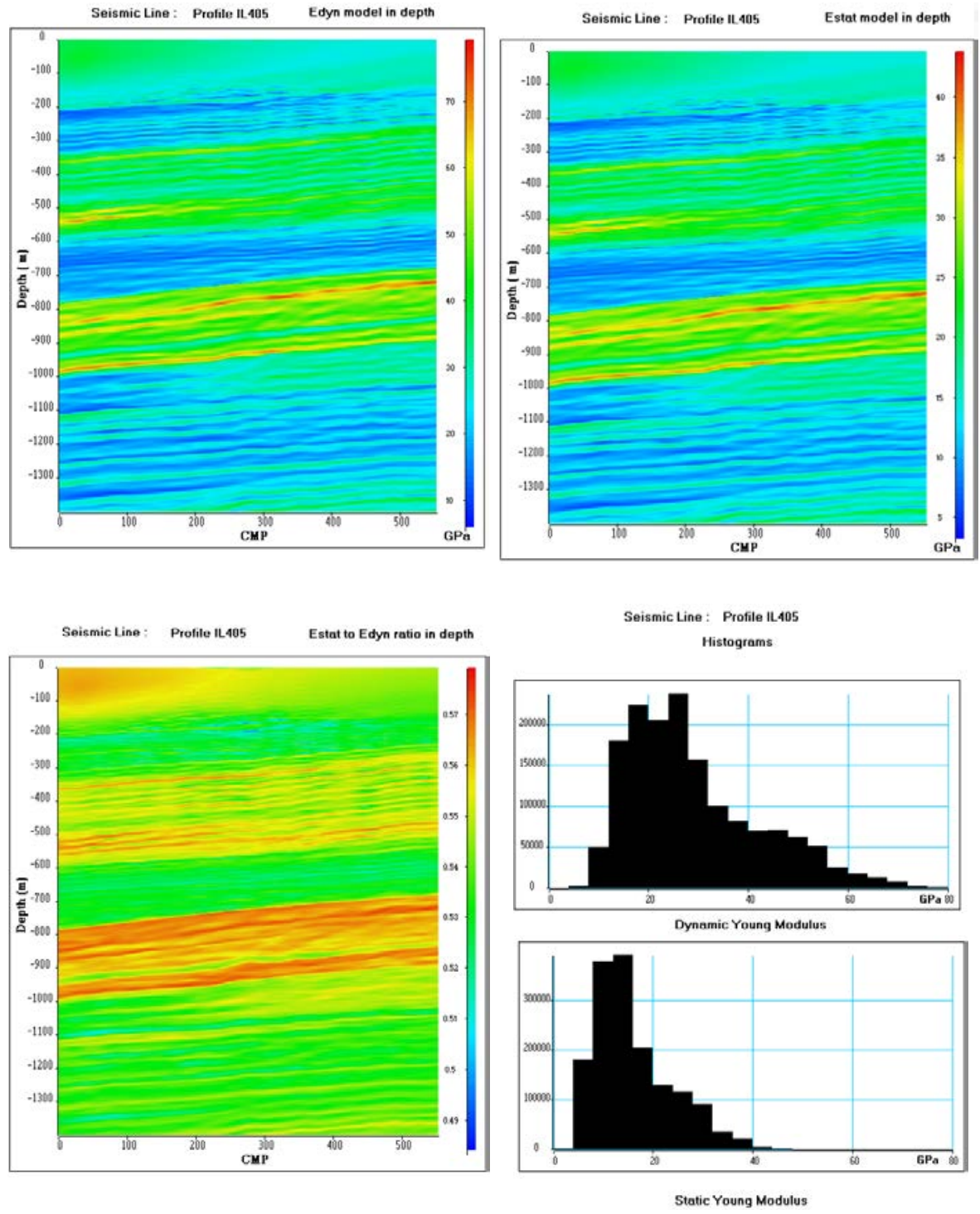

Figure 7.21 Seismic line IL405 - From dynamic to static moduli. Top: distribution of dynamic (left) and static (right) Young's moduli in depth. Bottom: Static to dynamic ratio in depth (left), Histograms of dynamic and static Young's moduli. 

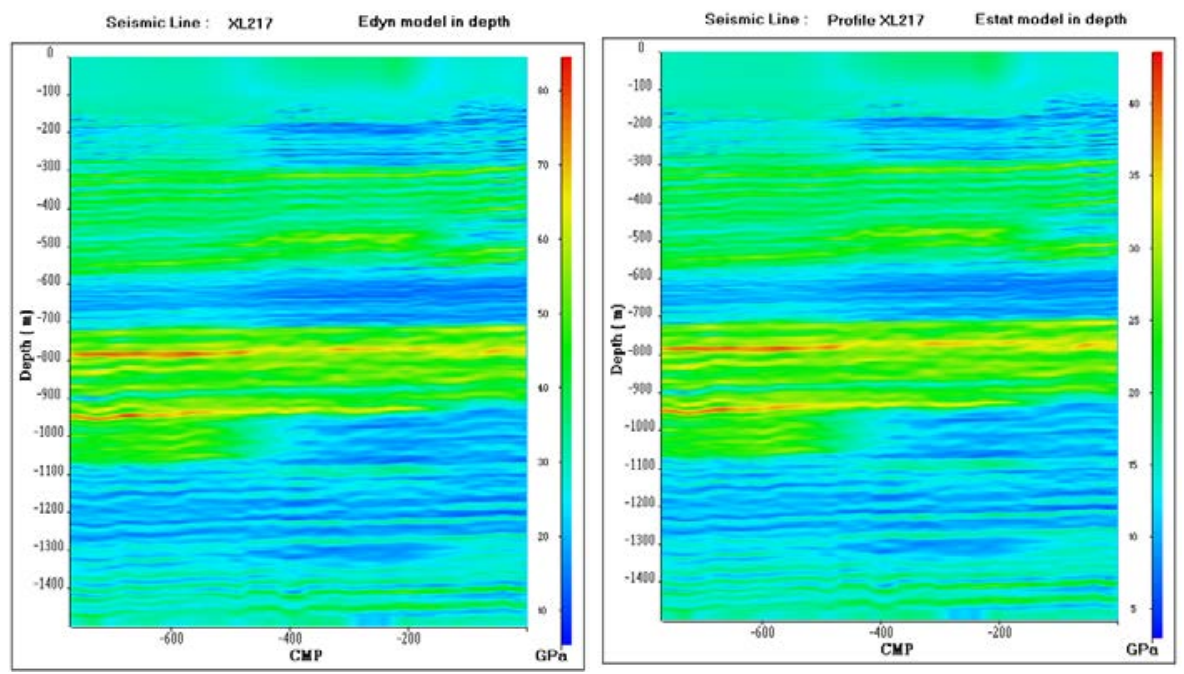

Seismic Line : Profile $\times 1217$

Seismic Line: Profile Xa217

Estat to Edyn ratio in depth Histograms:
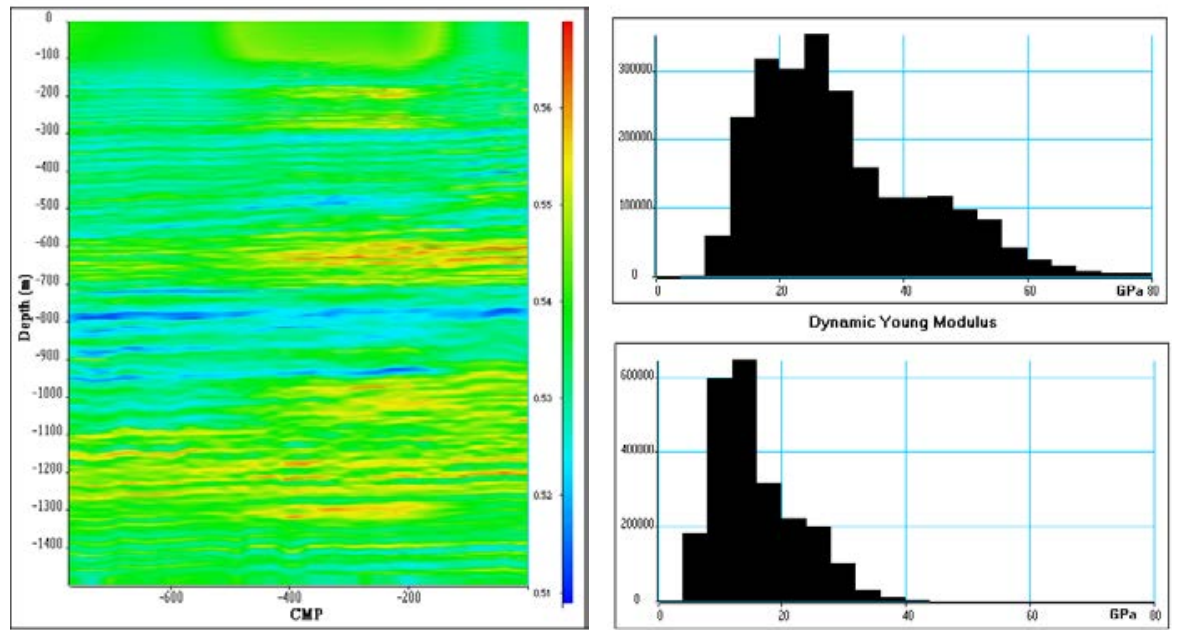

Dynamic Young Modulus

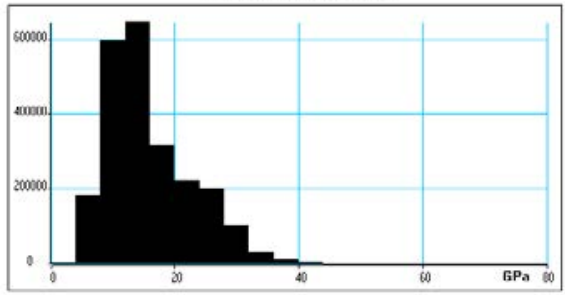

Static Young Modulus

Figure 7.22 Seismic line XL217 - From dynamic to static moduli. Top: distribution of dynamic (left) and static (right) Young's moduli in depth. Bottom: Static to dynamic ratio in depth (left), Histograms of dynamic and static Young's moduli. 


\subsection{Hydrogeological Study}

The impedance model (Ip block) can be converted into porosity using an empirical relationship between porosity and acoustic impedance established at well locations. To model porosities, another option is to use porosity at the well locations and interpolate between the wells by means of kriging. Partly due to the small number of wells, this outcome is very smooth and usually seems geologically consistent. More dense information can be integrated to improve the estimation of porosity. As porosity is linked to acoustic impedance, the use of dense seismic acoustic impedance information is relevant. A collocated co-kriging of porosity was thus conducted. The integration of the seismic information was performed using the normalized acoustic impedance as the secondary variable (Bourges et al., 2012). The use of a 3D cube makes it possible to provide 3D imaging of the connectivity of the porous bodies (Mari and Delay, 2011). Core analysis is usually carried out to establish porosity vs. permeability laws (Zinszner and Pellerin, 2007). It has been shown that it is possible to extract new attributes from seismic sections, leading to a better understanding of the distribution of the porous and permeable bodies (Mari and Guillemot, 2012). The attributes are also used to detect the impermeable layers.

At well locations, porosity vs. impedance cross plots were used to define linear laws between the two. The cross plots were obtained using density, acoustic velocity, and porosity (NMR) logs recorded in the wells. Two empirical relationships between porosity and acoustic impedance were used to convert the Ip impedance into porosity $\varphi$ depending on the density $\rho$ of the geological formation. The porosity is expressed in $\%$ and the acoustic impedance in $(\mathrm{m} / \mathrm{s}) .\left(\mathrm{g} / \mathrm{cm}^{3}\right)$. The density sections with a threshold of $2.48 \mathrm{~g} / \mathrm{cm}^{3}$ are used to select the law as follows (equation (7.10)):

- for the carbonated formations: $\rho \geq 2.48 \mathrm{~g} / \mathrm{cm}^{3}, \varphi=45.1097-0.0028 \mathrm{Ip}$,

- for the clayed formations: $\rho<2.48 \mathrm{~g} / \mathrm{cm}^{3}, \varphi=26.7678-0.0019 \mathrm{Ip}$

Laboratory experiments (Morlier and Sarda, 1971) have shown that the attenuation of a clean formation can be expressed in terms of three structural parameters: porosity, permeability and specific surface. Both theoretical and experimental studies have identified the relation between acoustic attenuation and petrophysical parameters:

$$
\delta=(C \cdot S / \varphi) \cdot\left(2 \pi \cdot k \cdot f \cdot \rho_{f} / \mu\right)^{1 / 3}
$$

With $\delta$ : attenuation $(\mathrm{dB} / \mathrm{cm}), f$ : frequency $(\mathrm{Hz}), \rho_{f}$ : fluid density, $\mu$ : fluid viscosity (centipoise)

$\varphi$ : porosity, $S$ : Specific surface $\left(\mathrm{cm}^{2} / \mathrm{cm}^{3}\right), C$ : calibration coefficient and $k$ : permeability $(\mathrm{mD})$.

Fabricius et al. (2007) found that the specific surface with respect to grain volume $(\mathrm{Sg})$ is apparently independent from porosity. In an attempt to remove the porosity 
effect on $\mathrm{Vp} / \mathrm{Vs}$ and mimic a reflected $\varphi$ vs. $\log (\mathrm{Sg})$ trend, they proposed the use of the following relationship between porosity $\varphi, \mathrm{Vp} / \mathrm{Vs}$ and $\mathrm{Sg}$ :

$$
\log (S g \cdot m)=a \cdot \varphi+b \cdot(V p / V s)+c \text { with } S g=S /(1-\varphi)
$$

where it should be noted that $\mathrm{Sg}$ is multiplied by $\mathrm{m}$ to make $\mathrm{Sg}$ dimensionless.

In practice, the parameter Ik-Seis (Indicator (I) of permeability (k) from acoustic or seismic (Seis) data) calculated from equation (7.13) is proportional to permeability k (Mari et al., 2018; Benjumea et al. 2019).

$$
\text { Ik-Seis }=(\varphi . \delta / S)^{3} / \mathrm{f}=(\varphi / S Q)^{3} / \mathrm{f}
$$

with f: P-wave frequency, Q quality factor, $\delta$ : attenuation, $S$ : specific surface and $\varphi$ : porosity.

The processing of the seismic lines was carried out to estimate the distribution of the velocities ( $\mathrm{Vp}$ and $\mathrm{Vs}$ ), the distribution of densities, the instantaneous frequency, the Q-factor (equation (7.6)), the porosity from acoustic impedance (equation (7.10)), the specific surface $S$ (equation (7.12)), and finally the Ik-Seis factor (equation (7.13)). In the domain of seismic frequencies, the Ik-Seis factor can only be seen as a relative indicator, varying from 0 for less porous and permeable bodies, up to 1 for more porous and permeable bodies.

If the porosity distribution is a key point for reservoir characterization, shale content is key both for the reservoir and the seal. Gamma ray logs are a very useful tool that can be computed from seismic data to estimate shale content. After several attempts with different seismic attributes such as P or S-wave velocity, density, seismic mechanical modules such as the shear modulus $\mu$, the matrix shear modulus appeared to be the most sensitive attribute to compute a pseudo gamma ray (Yven and Mari, 2014). The matrix shear modulus $\mu_{\mathrm{ma}}$ is given by the following formula:

$$
\mu_{m a}=\frac{\mu}{1-\beta_{B}}
$$

with $\beta_{B}$ being Biot's coefficient (1956) defined as follows: $1-\beta_{B}=(1-\varphi)^{m \varphi}$ and $m \varphi=\frac{3}{1-\varphi}$ with $\varphi$ the porosity.

The matrix shear modulus is corrected for the effect of porosity and can be converted into pseudo gamma ray (GR-Seis) by using an empirical relationship (polynomial function) between the gamma ray $\log$ and the matrix shear modulus established at the well locations.

The proposed procedure was applied on a 3D dataset. The results shown here were obtained on the XL217 cross-line. Figure 7.15 shows the instantaneous amplitude section and its associated SQI factor in depth. The SQI factor is low which means there is good confidence in the seismic amplitude and consequently in the elastic impedance in depth. In the 700-750 m range, one can notice a significant lateral 
variation of the seismic amplitude. The amplitude anomaly corresponds to the presence of a porous layer, between CMP 600 and CMP 400 at the top of the Dogger formation. Figure 7.23 (top) shows the specific surface and Ik-Seis distributions in depth. The interpretation is confirmed by a very low value of the specific surface and a high value of the Ik-Seis attribute. The high values of the specific surface are associated with the Callovo-Oxfordian (550-720 m depth interval). The pseudo gamma ray section computed from the Biot Shear modulus is shown in Figure 7.23 (bottom). We noted the lateral variation of the shale content in the Callovo Oxfordian.

\subsection{Conclusion}

The different steps involved in building a geo-model in depth can be summarized as follows:

- pre-processing must include QC on static corrections for the detection and compensation of long-wavelength anomalies,

- QC on seismic amplitudes and velocity models. Filtering of footprint anomalies. Quantification of amplitude quality (SQI factor) before pre-stack migration and inversion,

- processing: pre-stack time migration. At least three angle migrated stacks must be generated,

- elastic inversion to compute Ip and Is sections,

- computation of an a priori velocity model $\mathrm{Vp}$, assuming that the P-wave velocity $\mathrm{Vp}$ and the acoustic impedance Ip of a formation vary in a consistent way and a relationship between the two variables Ip and Vp exists. A single relationship or a relationship per range of impedances or per geological unit can be computed,

- update of the a priori $\mathrm{Vp}$ model, using the depth conversion of seismic horizons by a geo-statistical method which simultaneously uses Bayesian co-kriging and a multilayer model and which handles sources of uncertainty: Vp-update,

- depth conversion of the seismic blocks (amplitude, Vp-update, Ip, Is) using the updated velocity model Vp-update,

- computation of the density distribution in depth: $\rho=I p / V p$-update,

- computation of the shear velocity distribution: $V s=V p$-update $x$ (Is / Ip).

Knowledge of the density $(\rho)$ and velocity $(V p$-update, $V s)$ distributions allows the computation of mechanical dynamic modules such as the shear modulus, Young's modulus, bulk modulus and the Poisson's ratio. The conversion of dynamic Young's modulus into static Young's modulus was conducted.

We have described a method to build a geo-model in depth, using a $2 \mathrm{D}$ seismic line (07Est10) and 3D seismic lines (IL405 and XL-217) as examples. 

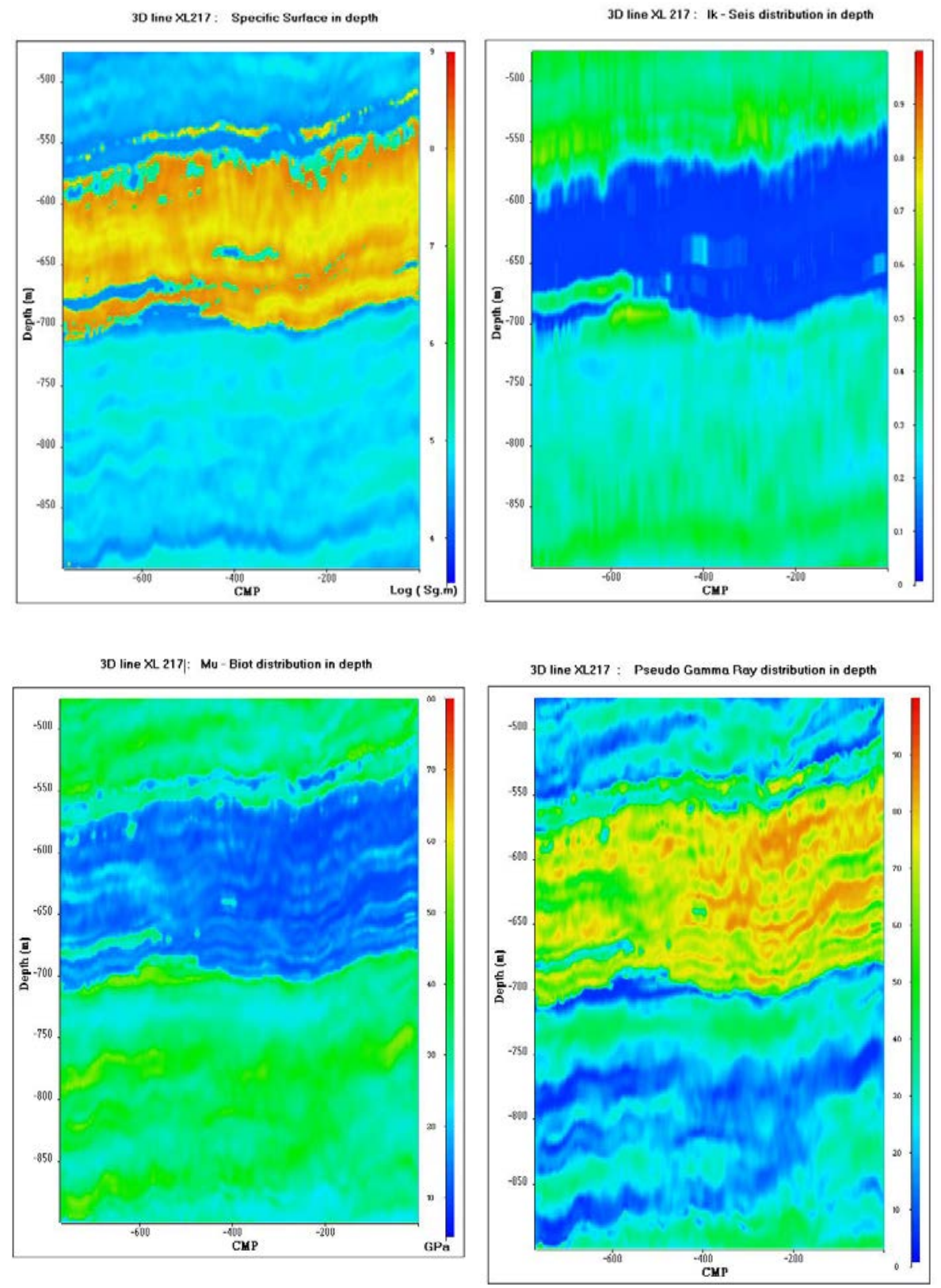

Figure 7.23 Mechanical and petro-physical parameter. Top: Specific surface and Ik-Seis distribution in depth. Bottom: Shear modulus and pseudo gamma ray distribution in depth. 
We have demonstrated the advantages of geo-statistical processing both to quantify the quality of the seismic amplitude (SQI) and to perform depth conversion (Bayesian Kriging).

The Q factor of geological formations can be obtained from VSP data. We made use of the fact that attenuation introduces dissipative dispersion, which can be measured from the frequency-dependent phase velocity of the VSP down-going wave. The methodology has been extended from well data to surface seismic data. For this purpose, a high-resolution velocity model is required. It is obtained by the elastic inversion of the seismic data and by conversion of acoustic impedance I $P$ into velocity $V p$. The procedure can be used to build a geo-model in depth defined by mechanical and hydrogeological parameters: velocities $(V p, V s)$, density, Q factor, porosity, specific surface and index of permeability (Mari and Yven, 2014).

The seismic procedure was extended to calculate a seismic pseudo gamma ray (GR-Seis). A highly porous layer was detected at the top of the Dogger, and lateral variation in shale content can be seen in the Callovo Oxfordian.

\section{Acknowledgements}

Many thanks to Andra for granting permission to use the datasets.

\section{References}

Andra (2005) Dossier 2005 Argile - Synthèse : Evaluation de la faisabilité du stockage géologique en formation argileuse - décembre 2005.

Andra (2009) Stockage réversible profond - Proposition d'une zone d'intérêt pour la reconnaissance approfondie et de scénarios d'implantation en surface - C RP ADP 09-0035.

Andra (2016) Dossier Option de Sûreté - Partie Exploitation (DOS-EXPL) CG-TE-D-NTE-AMOA-SR1-0000-15-0060.

André G., Hibsch C., Beaudoin B., Carpentier C., Fourcade S., Cathelineau M., Elion P., 2004. Oxfordian sedimentary dykes: Tectonic and diagenetic implications for the eastern Paris Basin, Bull. Soc. Geol. Fr, 175, 6, 595-605.

Benjumea B., Lopez A.I., Mari J.L., Garcia-Lobon J.L., 2019, Petrophysical characterization of carbonates (SE of Spain) through full sonic data, Journal of Applied Geophysics, 160, 1-14, https://doi.org/10;1016/J.appgeo.2018.10.024.

Bourges M, Mari J.L., Jeannée N., 2012, A practical review of geostatistical processing applied to geophysical data: methods and applications, Geophysical Prospecting, 60, 400-412, DOI: 10.1111/j.1365-2478.2011.00992.x 
Brigaud B., Vincent B., Carpentier C, Robin C., Guillocheau F, Yven B, Huret E., 2014, Growth and demise of the Jurassic carbonate platform in the intracratonic Paris Basin (France): Interplay of climate change, eustasy and tectonics, Marine and Petroleum Geology, 53, 3-29.

Castagna J.P., 1993, AVO analysis: Tutorial and review: in Castagna, J.P. and Backus M.M. (Eds.), Offset-dependent reflectivity - Theory and practice of AVO anomalies. Soc. Expl. Geophys., Investigations in Geophysics, 8, 3-36.

Connolly P., 1999, Elastic impedance, The Leading Edge, 18, 438-452.

Eissa E.A., Kazi A., 1988, Relation between static and dynamic Young's moduli of, rocks, Int. J. Rock Mech. Min. Sci. \& Geomech. Abstr., 25 (6), 479-482.

Fabricius I.L., Baechle G., Eberli G.P., Weger R., 2007, Estimating permeability of carbonate rocks from porosity and Vp/Vs, Geophysics, 72 (5), 185-191, DOI: 10.1190/1.2756081.

Garcia M.H., Rabaute A., Yven B., Guillemot D., 2011, Multivariate and spatial statistical analysis of Callovo-Oxfordian physical properties from lab and borehole logs data: Towards a characterization of lateral and vertical spatial trends in the Meuse/Haute-Marne Transposition Zone, Physics and Chemistry of the Earth, 36 (17-18), 1469-1485.

Gardner G.H.F., Gardner L.W., Gregory A.R., 1974, Formation velocity and density -- the diagnostic basics for stratigraphic traps, Geophysics, 39, 770-7

Gaumet F., 1997. Fondements géologiques pour la modélisation stratigraphique des systèmes carbonates. Le jurassique moyen de l'Angleterre à la Méditerranée. Thèse $3^{\mathrm{e}}$ cycle, Univ. Claude-Bernard, Lyon 1, 245.

Guillocheau F., Robin C., Allemand P., Bourquin S., Brault N., Dromart G., Friendenberg F., Garcia J.P., Gaulier J.M., Grodoy B., Hanot F., Lestrat P., Mettraux, M., Naplas, T., Prijac C., Rigollet C., Serrano O., Granjean G., 2000, Meso-Cenozoic geodynamic evolution of the Paris Basin: 3D stratigraphic constraints, Geodynam. Acta 13, 189-246.

Landrein P., Vigneron G., Delay J., Lebon P., Page M., 2013, Lithologie, hydrodynamisme et thermicité dans le système sédimentaire multicouche recoupé par les forages Andra de Montiers-sur-Saulx (Meuse), Bulletin de la Société Géologique de France, 184 (6), 519-543.

Lebreton F., Morlier P, 1983, A permeability acoustic logging, Bulletin of the International Association of Engineering Geology, 1, 101-105.

Mari J.L., Gaudiani P., Delay J., 2011, Characterization of geological formations by physical parameters obtained through full waveform acoustic logging, J. Phys. Chem. Earth, DOI:10.1016/jpce.2011.07.11.

Mari J.L, Guillemot D., 2012, Detection of porous and permeable formations: from laboratory measurements to seismic measurements, Oil \& Gas Science 
and Technology_Rev. IFP Energies nouvelles, 64 (4), 703-721, DOI: 10.2516/ ogst/2012209.

Mari J.L., Delay F., 2011, Contribution of seismic and acoustic methods to reservoir model building, in Lakshmanan Elango (ed.) Hydraulic Conductivity - Issues, Determination and Applications, InTech, 329-354, ISBN 978-953-307-288-3. Available from http://www.intechopen.com/articles/show/title/contribution-ofseismic-and-acoustic-methods-to-reservoir-model-building

Mari J.L., Yven B., 2014, The application of high resolution 3D seismic data to model the distribution of mechanical and hydrogeological properties of a potential host rock for the deep storage of radioactive waste in France, Marine and Petroleum Geology, 53, 133-153, Elsevier, DOI: 10.1016/j.marpetgeo.2013.10.014, http://dx.doi.org/10.1016/j.marpetgeo.2013.10.014

Mari J.L., 2015, Signal processing for geologists \& geophysicists, e-book, DOI:10.2516/ifpen/2011002, http://books.ifpenergiesnouvelles.fr/ebooks/ signal-processing/

Mari J.L., Lopez A.I, Benjumea B., Garcia-Lobon J.L., 2018, Shape index: a refraction attribute to detect fractures and permeable bodies, paper Th $\mathrm{J} 12,80^{\text {th }}$ EAGE annual conference, Copenhagen, Denmark.

Mari J.L., Yven B., 2018, Q factor estimation and validation: a new link between VSP and seismic lines, paper 557, CAJG, 1st Conference of the Arabian Journal of Geosciences, November 12-15 2018, Hammamet, Tunisia.

Megnien, C., 1980, Synthèse géologique du bassin de Paris, Mém. BRGM nº101, $\mathrm{n}^{\circ} 102, \mathrm{n}^{\circ} 103$.

Morlier P., Sarda J.P., 1971, Atténuation des ondes élastiques dans les roches poreuses saturées, Revue de l'Institut Français du Pétrole, 26 (9), 731-755.

Omre H., 1987, Bayesian kriging merging observations and qualified guesses in kriging. Math. Geol, 19 (1), 25-39.

Purser B.H., 1980, Sédimentation et diagenèse des carbonates néritiques récents, Tome 1. Technip, Paris, 366p.

Robein E., 2003. Velocities, Time-imaging and Depth-imaging in Reflection Seismics, Principle and Methods, EAGE publications bv, ISBN 90-73781-28-0.

Rocher M., Cushing M., Lemeille F., Lozac'h Y., Angelier J., 2004, Intraplate paleostresses reconstructed with calcite twinning and faulting: improved method and application to the eastern Paris Basin (Lorraine, France), Tectonophysics, $387,1-21$.

Sandjivy L., Shtuka A., 2009, Depth conversion and associated uncertainties using consistent velocity model: a probabilistic unified model based on Bayesian approach, paper presented at the $11^{\text {th }}$ International Congress of the Brazilian Geophysical Society, Salvador, Brazil, August 24-28, 2009. 
Shuey R.T., 1985, A simplification of Zoeppritz equations, Geophysics, 50, 609-614.

Shtuka A., Gronnwald T., Piriac F., 2009, A generalized probabilistic approach for processing seismic data, 79th annual SEG meeting, Expanded Abstracts.

Varela Carlos Lopo, Andre L.R. Rosa, Tadeusz J. Ulrych, 1993, Modeling of attenuation and dispersion, Geophysics, 58, 8, 1167-1173.

Walden A.T., 1991. Making AVO sections more robust, Geophys. Prosp., 39, 915942.

Whitcombe D.N., Connolly P.A., Reagan R.L., Redshaw T.C., 2002, Extended elastic impedance for fluid and lithology prediction, Geophysics, 67 (1), 63-67.

Wyllie M.R., Gregory R.J., Gardner H.F., 1956, Elastic wave velocities in heterogeneous and porous media, Geophysics, 21 (1), 41-70.

Yven B., Mari J.L., 2014, Sedimentology, petrophysics and 3D seismic contributions to the study of the eastern Paris basin formation (France), Doi: 10.3997/22144609.20140927, $76^{\text {th }}$ EAGE conference, Amsterdam RAI, The Netherlands.

Yven B., Mari J.L., 2018, Geomechanics: from core and logging to seismic lines, paper 556, CAJG, 1st Conference of the Arabian Journal of Geosciences, November 12-15 2018, Hammamet, Tunisia.

Zinszner, B., Pellerin, F.M., 2007. A geoscientist's guide to petrophysics, Éditions Technip, Paris. ISBN 978-2-7108-0899-2. 